\title{
Tópicos neoplatónicos en la poesía de Michelangelo Buonarroti
}

\author{
Sigmund MÉNDEZ ${ }^{1}$ \\ Universidad de Salamanca \\ sigmundmendez@yahoo.es
}

Recibido: $31 / 05 / 2013$

Aceptado: 30/06/2013

\section{RESUMEN}

Reconocidas tanto por su fuerza verbal como por su valor testimonial, las Rime de Michelangelo Buonarroti constituyen la más íntima expresión de su pensamiento. En este artículo se ofrece un análisis general de algunos contenidos e imágenes con la contextura de tópicos que provienen de la larga tradición neoplatónica, tanto en su raíz filosófica como en sus derivaciones líricas; en particular, se indagan ejemplos que atañen a dos vertientes fundamentales de la obra poética miguelangelesca: la amorosa y la de temática artística. A través del estudio de la recurrencia de conceptos y metáforas se intenta mostrar el nivel de pertinencia en el análisis de esta poesía en términos del neoplatonismo, para también, dentro de ese marco teórico, destacar su valor como manifestación cimera de la estética idealista del alto Renacimiento y la singularidad del pensamiento de Michelangelo como «idealismo demiúrgico».

Palabras clave: Michelangelo Buonarroti, Rime, neoplatonismo, teoría erótica, estética idealista.

\section{Neoplatonic Topics in Michelangelo Buonarroti's Poetry}

\begin{abstract}
Acknowledged as much for their verbal strength as for their testimonial value, Michelangelo Buonarroti's Rime are also the innermost expression of his thought. This article offers a general analysis of some contents and images as topics that have arisen from the long Neoplatonic tradition, both in their philosophical roots and lyrical derivations; particularly, it looks for examples concerning the two fundamental topics of Michelangelo's poetic work: the erotic and the artistic spheres. Through the study of recurrent concepts and metaphors, the adequacy of the Neoplatonic approach to his poetry is proven, but also, within this theoretical framework, we can evidence its value as an apical manifestation of idealistic aesthetic theory of the High Renaissance and the singularity of Michelangelo's thought as «demiurgic idealism».
\end{abstract}

\footnotetext{
${ }^{1}$ Facultad de Filología, Plaza de Anaya s/n., E-37001, Salamanca, España.
} 
Keywords: Michelangelo Buonarroti, Rime, Neoplatonism, Erotic theory, Idealistic Aesthetic.

SUMARIO: 1. Introducción 2. Concepciones e imágenes eróticas 2.1. Definiciones del amor 2.2. El Amor y sus «saetas visuales» 2.3. El ojo espiritual 2.4. El alma como esfera superior 2.5. La escala ontológica 3. Alegorías demiúrgicas 3.1. El corazón como lugar de las imágenes y de creación interior 3.2. El artista como demiurgo 3.3. La plasmación del concetto intelectual interior 3.4. La «substracción» de la materia 3.5. La visión sacrificial del cuerpo 4. Concepciones finales.

\section{INTRODUCCIÓN}

La poesía de Michelangelo Buonarroti (Caprese, 1475 - Roma, 1564) ocupa un sitio especial en la historia de la literatura artística $^{2}$ y la poesía italiana del Renacimiento. Junto con el mérito literario que de cierto llegan a poseer, las Rime han sido leídas además como plausible llave para el conocimiento de un hombre y de su estética. Se trata, por supuesto, de la obra «secundaria» de un artista de primer orden que conlleva el valedero testimonio de sus vivencias y sus concepciones como la estela de palabras que acompaña y refleja el proceso productor de las imágenes. En ese "creador total" que fue Michelangelo, la fase reflexiva de su labor adquiere una formulación verbal sin abandonar la propia esfera artística, desplegándose dentro de ella, en la poesía, como su legítimo vehículo ${ }^{3}$. Sus poemas pueden por ello ser destacados como expresiones interiores del gran proceso creador que fue, sin duda, el meollo significante de una vida consagrada al arte.

Para abordar la médula teórica de las Rime existen rutas de acceso más o menos delineadas. De forma relevante, ha sido reconocida desde el propio siglo XVI como herramienta exegética toral la gran clavis Platonis, según señalaba ya la declaración, muchas veces citada, de Francesco Berni (1934: 168) sobre la poesía de Michelangelo (que lo confirmaba, junto a su obra pictórica, como «nuevo Apollo e nuovo Apelle»):

${ }^{2}$ Usamos el término Kunstliteratur de la clásica obra de Schlosser (1924), quien por cierto no incluyó la poesía de Michelangelo. Sin embargo, Clements (1961) le reconoció importancia para discernir sus ideas estéticas y ha sido abordada destacando su valor teórico en la visión panorámica de Blunt (1994: 58-81); véase asimismo lo expuesto por FollieroMetz (1996), que adecuadamente pone de relieve su valor como «testimonio directo» de la teoría artística de Michelangelo.

${ }^{3}$ Véase lo indicado por Frey (Buonarroti 1897: vi). Según recuerda Clements (1961: xxxi): «Stressing this particular value of the Rime, Mariani [Valerio Mariani [1941]: La poesia di Michelangelo, Roma, Palombi, p. 60] writes that "Michelangelo never deigns to give a formulation [on art] other than a poetic one"». 
Ho visto qualche sua composizione:

Son ignorante, e pur direi d'avelle

Lette tutte nel mezzo di Platone.

(«Capitolo a fra Bastian dal piombo.» LXIII, 25-27) ${ }^{4}$

También el cándido apunte de Condivi (1998: 62) sobre la teoría erótica:

Io più volte ho sentito Michelagnolo ragionar e discorrer sopra l'amore, e udito poi da quelli che si trovaron presenti, lui non altrimenti dell'amor parlare, di quel che appresso di Platone scritto si legge. Io, per me, non so quel che Platone sopra ciò si dica, so bene che, avend'io così lungamente e intrinsicamente praticatolo, non senti' mai uscir di quella bocca se non parole onestissime e che avevan forza d'estinguere nella gioventù ogni incomposto e sfrenato desiderio che in lei potesse cascare.

Tal orientación neoplatónica fue asumida modernamente por autores como Ludwig von Scheffler, Borinski, Thode, Panofsky o Charles de Tolnay. Por su parte, Eugenio Garin (1966), reconociendo el «aura neoplatónica» de los textos de Michelangelo, ha indicado tanto la condición multiforme de esta corriente filosófica -en el propio medio florentino que, conjeturalmente, debió de ser para el artista mina fundamental ${ }^{5}$, , como la dificultad de establecer, en casos concretos, una explícita relación con fuentes directas. También a este propósito se ha destacado, aun por encima de la orientación neoplatónica, la herencia del «dantismo renacentista» (Folliero-Metz 2004: 59-68) de la que sin duda Michelangelo es exponente notable. Tampoco dejaron de ponerla de relieve las fuentes del siglo XVI, indicando el peso de «il suo famigliarissimo Dante», según dice Vasari (1986: II, 908), cuya obra «ha tutta nella memoria, sempre dinanzi agli occhi», apuntaba Varchi (1960': 5), «del qual è sempre stato studioso», confirmaba Condivi (1998: 48) e ilustra la propia discusión especializada que dirige en los Dialogi de Giannotti (1939: 40) donde se le encomia como «gran dantista»"

Sin escatimarle un ápice a la importancia de ese influjo dantesco, cabe afirmar que el complejo sistema ideatorio e imaginario del neoplatonismo reviste una relevancia principal para iluminar el arte y la poesía de Michelangelo. Así, con todo

${ }^{4}$ Cabe notar por cierto que el texto laudatorio ha sido leído por Campbell (2002: 598599) en términos irónicos (incluso compartidos y avalados por el maestro: núm. 85, 37-39; Buonarroti 1960: 48), con vistas a la modalidad de Berni como una suerte de poète maudit, que respecto de sí mismo perfiló incluso un talante contrario al divinus furor de una cierta «manía obscura» («Vero spirito d'inferno per amore», LXV; Berni 1934: 175).

5 El vario influjo del neoplatonismo florentino irradiado por el círculo en torno a Lorenzo de' Medici (Ficino, Landino, Poliziano, etcétera) es el que suele invocarse a este propósito. Giannotti (1939: 66) pone en boca del artista: «in Firenze non era huomo litterato che non fusse mio amico».

${ }^{6}$ Es una relación muy notoria; por ejemplo, Byron (1948: 451b) hará decir al poeta de la Commedia: «The Stream of his [Michelangelo's] great thoughts shall spring from me» (The Prophecy of Dante IV. 67). 
lo prudentes que puedan juzgarse las reservas de Garin, e incluso si diversos paralelismos se atribuyen, más que al conocimiento erudito, a una gran intuición o a una especial «afinidad de espíritu», es posible encontrar testimonios de concurrencia metafórica y conceptual no desdeñables de ser invocados para delimitar, frente a ellos, los elementos distintivos de una nueva formulación. Ciertamente, el «(neo)platonismo» lo ha heredado Michelangelo, además de su probable manejo de textos en toscano de Poliziano, Landino, Ficino o - alumno de este- Francesco Cattani da Diacceto ${ }^{7}$, también de esa corriente central de la lírica amorosa tardomedieval y renacentista — que es, en buena medida y desde cualquier punto de vista, un platonismo de "segundo" o "tercer grado"-, que maneja tópicos desprendidos de su original esfera especulativa y que han configurado, desde siglos atrás, un lenguaje «subfilosófico» (Summers 1988: 14-17) saber instrumentado al servicio del rescate de una «fantasía erótica» emparentada con el arte y la búsqueda general de la belleza ${ }^{8}$. Asimismo, en tal despliegue, se trata de un Platón parcialmente asimilado o asimilable, según ya sugirió la Patrística —en particular, para la Edad Media, san Agustín-, al propio cristianismo, siendo, como dijo Petrarca, el más alto entre los paganos «en asuntos divinos» y el «más próximo» a la verdad ${ }^{9}$; la tendencia sincrética entre ambas tradiciones adquiere nueva vigencia en el Renacimiento y, en este sentido, es atribuible al arte de Michelangelo ${ }^{10}$. Por su parte, la herencia bíblica y de la teología medieval o algunas corrientes espirituales de su tiempo (de Savonarola a la Contrarreforma), no menos que la propia poética toscana suponen también fuentes primarias donde el artista se inspiró para modular su propio lenguaje $\mathrm{e}^{11}$. Michelangelo es, en todo caso, un poeta y un "neoplatónico"

${ }^{7}$ Con este último tuvo al parecer un fecundo contacto Michelangelo a través de la Accademia Sacra dei Medici, y es una de las "fuentes directas" conjeturales del neoplatonismo del artista, detectable en algunos de sus trabajos; véase Pernis (1993: 150151) y Van den Doel (2008: 191-192).

8 «Also dieser Plato bedeutet zunächst nichts anderes als den Schutzheiligen der Schönheit für die Phantasie, im Kerne natürlich die erotische Phantasie und ihre sinnfällige Tochter die Kunst» (Borinski 1908: 13).

9 «In divinis altius ascendit Plato ac platonici, quanquam neuter pervenire potuerit quo tendebat. Sed, ut dixi, propius venit Plato, de quo nullus cristianorum et in primis Augustini librorum fidelis lector hesitaverit» (De sui ipsius et multorum ignorantia IV; Petrarca 1975, II: 1118).

${ }^{10}$ Por ejemplo, según anotaba De Tolnay (1948: 74) sobre la Capilla Medici: «It is not surprising to find the fundamental theme of Phaedo in the Medici Chapel when one realizes that this Chapel was consecrated to the Resurrection of Christ, prototype of resurrection. Now the Neoplatonic philosophy of the Renaissance considered the Platonic doctrine of the rebirth of the soul as found in the Phaedo as a prophecy of the Christian doctrine of resurrection». Véanse también las interpretaciones neoplatónicas de Panofsky (1962) y Balas (1995: 158), para quien: «Michelangelo's handling of complex allegory, his exploitation of pagan imagery, were thoroughly in the Neoplatonic tradition, and expression of the pia philosophia».

${ }^{11}$ Condivi (1998: 17 y 61-62) apuntaba su lectura de Dante, Petrarca, Boccaccio, el Antiguo y el Nuevo Testamento y Savonarola. 
sui generis ${ }^{12}$-aunque ¿no lo fueron también, a su muy personal manera, Pico o Cusa, Poliziano o Lorenzo de' Medici, Leone Ebreo o Francesco Patrizi?, por no hablar de los antiguos y medievales adscritos a esta milenaria "escuela"-, cuya poderosa personalidad artística no ha dejado —en este territorio "ajeno"- de expresarse con una voz, si bien de relativa medianía, de cierto original e inconfundible en el centenario coro de la gran tradición lírica toscana, y que sugiere el derrotero hacia las nuevas tentativas de una más compleja elaboración de los contenidos y "obscurecimiento" emprendidos a mediados del Cinquecento y prefigurativos del conceptismo del XVII ${ }^{13}$.

En sintético atisbo, debe destacarse que la poesía de Michelangelo constituye un valioso testimonio del despliegue de su pensamiento y su obra plástica que asimismo refleja la época en la que se enmarca y sus transformaciones. Hay varias fases poéticas más o menos bien definidas, como ha anotado Girardi, desde una primera etapa con ejercicios más exploratorios e incidentales (1500-1532/34), a otra de madurez con un mayor compromiso técnico en su trabajo literario y superior densidad conceptual que termina con la muerte de Vittoria Colonna (1534-1547) y que desemboca en el período último con un paulatino desprendimiento de la labor poética (1547-1560). De manera correspondiente, el desarrollo de su pensamiento va desde una más marcada tendencia neoplatónica en su vertiente estética, con una confianza mayor en la belleza como espejo divino y el amor como válida vía espiritual (primeros trabajos escultóricos, techo de la Sixtina), a un ahondamiento en la naturaleza "alegórica" del arte que problematiza la fenomenicidad en busca de la expresión de lo divino invisible (el Giudizio), con una concomitante intensificación de la temática mística del neoplatonismo, para dar lugar, finalmente, a los rigores de un ascetismo cristiano que "desrealiza" lo corporal como signo transfigurado de lo transcendente (el paso de la nuditas virtualis del David, el Adán de la Sixtina o la Pietà de San Pedro a la estilización de la Pietà Rondanini; cf. Blunt 1994: 58-61 y Snow-Smith 1998), reflejándose también con ello el tránsito epocal de la Florencia de los Medici a la Italia postridentina.

En las modalidades propias a su expresión, la obra de un poeta cifra en sí misma una estética. Discernir esta desde aquella implica enfrentar la plasticidad y cualidad connotativa del lenguaje figurado que también obedece a sus propias convenciones escriturales; pero es precisamente en su contraste con ellas desde donde se perfila su singularidad. Cabe decir que la poesía miguelangelesca se caracteriza por la "densidad" de su substancia verbal y conceptual que da cuenta, en palabras y cláusulas marmóreas, del agonismo entre la materia y el espíritu en una obra cuya

12 Hay de cierto en él una profunda y compleja adaptación personal de tópicos, contenidos y símbolos neoplatónicos, destacada por Panofsky (1962: 182): «Michelangelo's works reflect this Neoplatonic attitude not only in form and motifs but also in iconography and content... Michelangelo resorts to Neoplatonism in his search for visual symbols of human life and destiny as he experienced it».

${ }^{13}$ Una buena introducción general a Michelangelo como escritor tanto epistolar como lírico es la que ofrece Girardi (1966). 
constancia se extiende enlazando el Renacimiento y el Barroco. La creación poética cifra la labor artística y despliega sus figuraciones tocando a menudo la temática erótica, convirtiéndose ambas en mutuo espejo metafórico. Es ahí donde se encuentran las claves que definen el arte verbal de Michelangelo. En qué medida la lírica es tributaria del neoplatonismo (y/o el dantismo) y cómo es que este complejo hacedor de formas se ha apropiado y ha transfigurado tan vastas y complejas herencias, es algo que solo puede ser elucidado a partir del estudio de algunas destacables imágenes y nociones en sus propios textos. Con vistas a ponderar la operatividad de dicho código conceptual en la poesía miguelangelesca, el presente texto ofrece un análisis panorámico de algunos notorios tópicos en esas dos vertientes centrales y estrechamente entrelazadas: la erótica y la "demiúrgica" (que reflexiona sobre el hacer artístico, sello distintivo del artista-poeta).

\section{CONCEPCIONES E IMÁGENES ERÓTICAS}

\subsection{Definiciones del amor}

De manera casi inexcusable, en varios poemas se señala el origen sensible de la experiencia amorosa; por ejemplo, en esta pregunta retórica de un madrigal dirigida al Amor:

Che cosa è questo, Amore,

c'al core entra per gli occhi,

per poco spazio dentro par che cresca? $(8,9-11)^{14}$

Aquí se hace patente, en primera instancia, una concepción tradicional en el sentido de la célebre definición de Andreas Capellanus (1892: 3) y su tránsito de lo sensible a lo anímico: "Amor est passio quaedam innata procedens ex visione et immoderata cogitatione formae alterius sexus» (I, I; «El amor es una cierta pasión ingénita que procede de la visión y la cogitación excesiva de la forma del otro sexo»). El camino que sigue desde su origen visual hasta su resguardo en la memoria lo expuso así Nicolò de' Rossi (1974: 72):

Amore è uno accidente che façe en süo simil ultra modo affecto; nasce dagli ogli cum sensibel paçe, nutrise en core, non cum'en subieto; posa, dove reminesencia iaçe, quasi per spera cerne 'l suo obieto. (CXXXVI, 3-8)

${ }^{14}$ Las Rime de Michelangelo se citan según la edición de Girardi (Buonarroti 1960), indicando número de poema y versos. 
Según muestra el poema miguelangelesco, el proceso corresponde a la apropiación de la forma exterior (la de la amada, en este caso), que pasa a través de los ojos al repositorio del corazón ${ }^{15}$, donde se convierte en phantasía, en el sentido aristotélico de imago in absentia rei ${ }^{16}$.

Más sugestiva es acaso la posterior definición cifrada en el terceto de un soneto inconcluso («Quanta dolcezza al cor per gli occhi porta...»):

Amore è un concetto di bellezza

immaginata o vista dentro al core,

amica di virtute e gentilezza. $(38,9-11)$

El editor Guasti (Buonarroti 1863: 4) vinculó estos versos (considerándolos, de modo no del todo descartables, como un epigrama independiente) ${ }^{17}$ con el inicio del soneto de Dante Amore e 'l cor gentil sono una cosa... (Vita nova, XI [XX], 3, 1; Alighieri 1996: 108), que refiere directamente el célebre aserto de il saggio Guido Guinizzelli (2002: 33) sobre la relación necesaria entre el amor y el corazón gentil (V: Al cor gentil rempaira sempre amore...), equiparable a la que tiene el alma racional con la razón. Esto corresponde, en efecto, a la idea medieval del amor cortés como propio, no de sensibilidades rudas, sino de los "corazones gentiles" capaces de acogerlo. Sin embargo, el núcleo de la definición señala al amor como «concepto de belleza imaginada o vista», es decir, como una "forma" (= concetto) de lo bello imaginariamente configurada o vista - con la acies cordis - en el corazón. Esta contextura es iluminada por viejas enunciaciones sobre el amor en la tradición poética italiana, como la que incluye el soneto anónimo - atribuido a Dante- «Molti volendo dir che fosse amore»: «ardore / De mente per pensiero» (56; Frati 1913, II: 158), que relaciona el reconcomio mental-imaginario con la naturaleza ígnea del deseo, vínculo no pocas veces repetido ${ }^{18}$. Es asimismo notorio

${ }^{15}$ De acuerdo con Leone Ebreo (1929, [III], fols. 1v-2r), la imagen de la amada atraviesa desde los ojos a los diversos sentidos interiores, incluyendo la phantasía, hasta instalarse en el «centro del corazón», «el corazón de la mente»: «che se la splendida bellezza tua non mi fusse intrata per gl'occhi non me ne harebbe possuto trapassar'tanto, come fece il senso, e la fantasia, et penetrando sino al cuore non haria pigliata per eterna habitatione come pigliò la mente mia, impiendola di scultura di tua immagine, che cosi presto non trapassano i raggi del Sole i corpi celesti o gl'elementi, che son'disotto fino a la terra, quanto in me fece l'effigie di tua bellezza, fin'a ponersi nel centro del cuore, e nel cuore de la mente».

${ }^{16}$ Según consigna Equicola (1536: fol. 114v): «Quella potentia che è in noi, la quale s'allegra over s'attrista delle cose presenti si chiama senso: quando fa il medesmo delle preterite o future, se li dice imaginatione» (IV, «De sensu»).

${ }^{17}$ Epigrammi ed epitaffi, v, con variantes en el segundo verso: «Amore è un concetto di bellezza / Immaginata, cui sta dentro al core, / Amica di virtute e gentilezza» (Buonarroti: 1863: 4); véase la nota filológica de Girardi (Buonarroti 1960: 190-191).

${ }^{18}$ Por ejemplo, Cecco d'Ascoli (1927: 209) en L'acerba II, XI: «O quanto è forte l'amorosa fiamma / Che vien da immaginar di cosa bella / Che per disio tutto il cor s'infiamma!» (II, XI. 1347-1349). El amor tiene sobre todo un origen en los ojos, pero puede 
que en su parte primera la definición miguelangelesca concuerda con las tesis propias a la erótica renacentista de corte neoplatónico, según muestra Leone Ebreo (1929, [III], fol. 98r) para quien «nasce l'amore concetto dal bello ne la mente del suo conoscente a chi manca, et il desidera». Sus antecedentes se remontan a la Antigüedad y un notable ejemplo afín lo encontramos en Apuleyo, en la oración de Lucio dirigida a Isis: «divinos tuos vultus numenque sanctissimum intra pectoris mei secreta conditum perpetuo custodiens imaginabor» (Metamorphoses XI, 25, 1012; «a tus divinos rasgos y tu numen santísimo imaginaré sagrado dentro de los lugares secretos de mi pecho como perpetuo custodio»). Por su parte, Michelangelo sugiere en los versos citados su marcada tendencia idealista al mostrar que el amor es propiamente el concetto que se tiene de esa belleza imaginada o vista interiormente, esto es, el meollo ideal de una representación fantástica de la belleza.

\title{
2.2. El Amor y sus "saetas visuales"
}

En el contexto erótico de la «imposición», imprevista y violenta, de la belleza al corazón amante, esta se suele expresar a través de la metáfora de los ojos de la amada como lugar desde donde Amor lanza sus implacables saetas:

\author{
Sotto duo belle ciglia \\ le forze Amor ripiglia \\ nella stagion che sprezza l'arco e l'ale. \\ Gli occhi mie, ghiotti d'ogni maraviglia \\ c'a questa s'assomiglia, \\ di lor fan pruova a più d'un fero strale. $(131,1-6)$
}

Es una imagen que responde, en efecto, a un viejo tópico. Su historia se remonta al pensamiento y la literatura de Grecia. Téngase en cuenta la antigua idea de los ojos compuestos por fuego ${ }^{19}$, cuya luz emitida permitía ver ${ }^{20}$; son por ello phosphóra (Timaeus 45b3), «portadores de luz», según las teorías activas de la visión, avaladas por Platón y muy difundidas en la Antigüedad. Asimismo, hay que tomar en cuenta la preponderancia de la vista en los procesos del enamoramiento («Gli occhi esser guida de nostro amar non dubitamo»; Equicola 1536, fol: 131v); según dice Platón, tanto la «emanación» como la «corriente de la belleza» que surge del amado y retorna a él desde el amante pasan «a través de los ojos» (Phaedrus $251 \mathrm{~b}$ y $255 \mathrm{c})$. Su importancia en dicho proceso es fundamental; según Plotino:

operar también «sin la vista» de modo interior: «Senza vedere, l'uom può innamorare / Formando specchio della nuda mente / Veggendo vista sua nel 'maginare» (III, I, 1959-1961; Cecco d'Ascoli 1927: 248).

${ }^{19}$ Alcmeón de Crotona, DK 24 A 5 = Teofrasto, De sensu et sensibilibus 26.

20 Como al parecer creía Empédolces, de acuerdo con Aristóteles: De sensu et sensibilibus $437 \mathrm{~b} 23-438 \mathrm{a} 3=$ DK $31 \mathrm{~B} 84$. 
A partir en efecto de lo intensamente ejecutado por la contemplación y de tal clase de influjo desde lo observado habiéndose colmado el ojo, como una visión con su imagen, se formó verosímilmente el Amor, y acaso su denominación de allí más bien incluso ha surgido, porque a partir de la visión [hórasis] tiene su existencia. (Enneades III, 5, 3, 11-15)

El amor surge de los "influjos" que provienen del objeto de su contemplación y su propio reconcomio; es como un "ojo colmado" e incluso tiene una supuesta «etimología» común con la "visión" (Éros / hórasis) ${ }^{21}$.

Estos elementos pueden explicar el sentido de la referida metáfora en este contexto específico, como de hecho aparece ya en pasajes de la literatura clásica; así en Esquilo:

y a las bien formadas delicadezas de las vírgenes todo aquel que pasa envía de su mirada la flecha hechicera, vencido por el deseo. (Supplices 1003-1005)

el dulce dardo de los ojos, la flor del deseo que devora el corazón. (Agamemnon 742-743)

En el período tardío, la novela de temática amorosa sería el ámbito más propicio para desarrollar la alegoría erótico-visual que pasará luego a la Edad Media. En la poesía italiana, Dante tiene ejemplos de la imagen de los ojos de la amada — «balconi della donna [l'anima] che nel dificio del corpo abita [...] finestra delli occhi»: Convivio III, VIII, 9-10, 47-48 y 55; [Alighieri 1995: 198]- que "hieren" con sus "inflamados espíritus" (rayos visuales / espíritus amorosos) al amante:

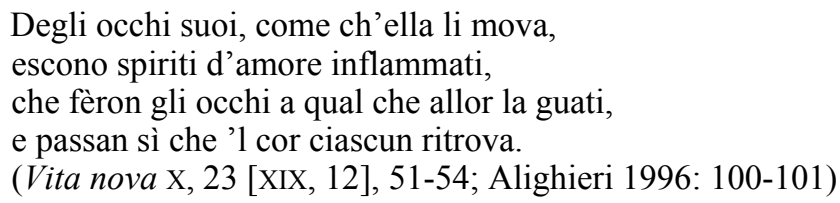

Tales “inflamados espíritus”, o igniculi («faville»: XLVI, 74; Alighieri 1965: 70), podían también provenir, de modo conveniente para las concepciones eróticas, del corazón. Además, a la vista corresponde el propio atalaya del dios Amor desde donde «lanza sus armas»; así los ojos de Beatrice (las "esmeraldas"), que sirven de espejo para contemplar al Grifón (Cristo):

${ }^{21}$ No olvidó señalarlo Diacceto (1561: 108): «Et però habbiamo ad intendere l'Amore essere un'appetito, che seguita la cognitione visuale. Onde Plotino dice rettamente l'amore havere acquistato il nome dalla visione» (III, II). 
Disser: "Fa che le viste non risparmi;

posto t'avem dinanzi a li smeraldi

ond' Amor già ti trasse le sue armi".

(Purgatorio XXXI, 115-117; Alighieri 1967, III. 545) ${ }^{22}$

O bien, en un soneto atribuido (Alighieri 1984: 2):

Alló $\cdot$ gli pia[c]que, non per voglia mia, Che di cinque saette mi piagasse.

La prima à non' Bieltà: per li oc[c]hi il core

Mi passò [...]. (Il Fiore, [Sonetti] I: 7-10)

Y Cavalcanti (1986: 66-67):

O tu, che porti nelli occhi sovente

Amor tenendo tre saette in mano [...]

la quale [anima] ha già feruta nella mente

di due satte l'arciere soriano ${ }^{23}$. (Rime XX, 1-2: 5-6)

Con numerosas continuaciones, como en Ariosto (1998: 907):

Chi salirà per me, madonna, in cielo

a riportarne il mio perduto ingegno?

che, poi ch'uscì da' bei vostrí occhi il telo

che 'l cor mi fisse, ognior perdendo vegno.

(Orlando furioso XXXV, 1a-d)

Próxima al poema de Michelangelo es la imagen específica de la "ventana"24, abierta al ataque de Amor, del modo en que ha sido difundida también por Petrarca (1951:125):

${ }^{22}$ Benvenuto da Imola (1887: IV, 237) comenta así la terzina: «dissero: fa' che non risparmi le viste, idest, nunc intende et exacue virtutem visivam, quia, posto t'avem dinanzi alli smeraldi, idest, ante oculos pretiosos Beatricis, onde, idest, a quibus, Amor, scilicet, Cupido filius Veneris, già ti trasse le sue armi, idest, olim immisit sua tela in te, quia percussit te utraque sagipta, primo aurea in pueritia, quando primo amoratus es de ea, deinde plumbea, quando postea deseruisti eam». La cualidad activa de los «rayos visuales»se sugiere en otros pasajes de las obras de Dante; por ejemplo: «De gli occhi suoi gittava una lumera, / la qual parëa un spirito infiammato» (Rime XXII [LXIX], 5-6; Alighieri 1965: 72).

${ }^{23}$ Cf. Cavalcanti (1986: 79 y 112-113; XXIV, 9-10 y XXIX, 9-10, 12-13).

${ }^{24}$ Sobre ello, en efecto, está el antecedente de la voz griega opé. En latín se usa también figuradamente «ventanas» o bien «puertas»; así Lucrecio: «per eos [oculi] animum ut foribus spectare reclusis» (De rerum natura III, 360). En Leonardo da Vinci (1995: I, 142): «finestra dell'anima»; «janellas dos homens e o principal indicio do que ha dentro d'elles», dice Francisco de Holanda (1930: 110); etcétera. 
Io avrò sempre in odio la fenestra onde Amor m' avventò già mille strali [...]. (LXXXVI, 1-2)

La saeta de Amor tiene además, como ya se ha visto, la virtud de «clavar» la imagen de la amada en el corazón del amante; según Nicolò de’ Rossi (1974: 84):

\author{
volse ch'Amor de questa leçadreta \\ mi saetasse cum l'aorea saeta \\ dentro nel core sua figura bella [...]. (CLX, 4-6)
}

Francesco Colona (2004: I, 146) recurre a la imagen en su larga descriptio de Polia: «Cum dui chiarissimi poscia \& sagittanti ochii [...] nel mio core come demisso dardo da irato Cupidine profundamente uulnerabondo». No la olvidó Bembo (1991: 271): «chi non sa fare incontanente quella che egli ama saettatrice, fingendo che gli occhi suoi feriscano di pungentissime saette?» (II, VIII, 51-52).

En términos generales, y de acuerdo con la teoría visual activa, se atribuyen a los ojos los mayores poderes con respecto al origen de la belleza sensible como auténticos emisores de luz; por ello el resplandor de los metales y las piedras preciosas - a los que se podía atribuir «luz propia» - pueden ser señalados por Michelangelo como dependientes de esa virtud iluminativa:

Ogni gemma più luce

dagli occhi suo che da propia virtute. $(115,6-7)$

Aunque tales materiales participan de la naturaleza del fuego (pues pone «il fuoco la lustreza, o vero lucidità, con li razi che si truovono ne le pretiose pietre»; Leone Ebreo 1929: [II], fol. 12r), son inferiores al poder vital-espiritual de la mirada; también el amor revela su superioridad implicando la participación de la vista en términos no solo sensibles, sino anímicos. Asimismo, la tratadística erótica consignó la superioridad del «fuego amoroso» sobre el elemental; este quema solo tocándolo, mientras que aquel «hiere de lejos» por la vista y la phantasía: «Per la qual cosa appare il fuoco d'amore esser piu vehemente, che lo elementato: questo non consuma: se non tocca, \& è propinquo come Ciro appo Xenophonte narra: quello da longi, \& da presso è nocivo, et col vedere, et con la imaginatione ne distrugge» (Equicola 1536: fol. 131v). En este punto, Michelangelo muestra también su inclinación a remarcar la potencia y cualidad dinámica de la vista a partir del principio activo del alma destacado por las doctrinas neoplatónicas.

\title{
2.3. El ojo espiritual
}

En el soneto Ben possom gli occhi mia presso e lontano..., se resalta a la visión del amante en el sentido propio del neoplatonismo, es decir, en las posibilidades espirituales que se abren a través de la arrobada contemplación erótica: 
L'anima, l'intelletto intero e sano per gli occhi ascende più libero e sciolto a l'alta tuo beltà; ma l'ardor molto non dà tal previlegio al corp' umano. (166, 3-8)

Se entiende que la «alta tuo beltà» corresponde a la procedencia originalmente transcendente de la belleza, que impulsa el movimiento ascensional del "alma intelectiva", desatando con ello la pugna con la parte corpórea del hombre en los términos propios al agonismo carne / espíritu de la doctrina platónica y el ascetismo cristiano. Pero la "solución" que propone el yo lírico, en su súplica a Dios, es verse tornado entero en ojo: «fa' del mie corpo tutto un occhio solo» $(166,13)$. Con ello, la vista confirma su estatus privilegiado a modo de facultad "transensible" y espiritual que, contrariamente a las inclinaciones descendentes connaturales a la carne, le permite remontarse libremente al «intelecto íntegro y sano» hacia esferas más altas como instrumentum contemplationis; por ello puede figurar, en efecto, no solo a lo divino sino al Bíos theoretikós como el ojo purificado que lo mira: «pues este es el ojo único que mira la gran belleza» (Plotino, Enneades, I, 6, 9, 24-25). El intelecto mismo - como dice Diacceto (1561: 106) - «è veramente un'occhio eterno, che vede ogni cosa, Signore del mondo, temperatore delle cose celesti, \& terrene» (III, II); así, el amor más alto, el que da la verdadera beatitud, es el que se alcanza contemplando «la vera bellezza con l'occhio della mente, col quale solo puo essere veduta, non producendo imagine e similitudine di virtù, ma vere virtù, fatto a Dio amico» (Diacetto 1561: 161). En la versión de Michelangelo, esto correspondería a su vez a la modalidad "absoluta" de un alma convertida por entero en el total «ojo colmado» (Enneades III, 5, 3, 13) con el amor «teórico». La vista es entendible como un vehículo superior de conocimiento pues aprehende las cosas, en cierta medida, "desmaterializadas", convertidas en «luz» interior que se dirige hacia lo más alto ${ }^{25}$. Por ello se reclama la "iluminación" de la pureza contemplativa como vía ascendente; asimismo, la receptividad respecto de la hermosura resulta plausible en la medida en que esta se estima como manifestación de un principio divino que abre, desde la mirada que mira la mirada, el camino hacia su fuente («de gli occhi tuo rubati al paradiso. / La tuo beltà non è cosa mortale, / ma fatta su dal ciel fra noi divina»; 78, 8-10).

\subsection{El alma como esfera superior}

La bella figura amada corresponde, en términos neoplatónicos, a la impronta o reflejo terreno de la Idea que le da sustento y que, también en la concepción

${ }^{25}$ Bien lo expone Lomazzo (1974: I, 227): «Perché tutto questo ordine del mondo che si vede pigliasi dagli occhi, non in quel modo ch'egli è nella materia dei corpi, ma in quel modo ch'egli è nella luce che negli occhi è infusa. E perché egli è in quella luce, separato già dalla materia necessaria, e senza corpo, tutto l'ornamento di questo mondo per la luce s'offerisce» (XXVI, IV). 
dantesca y petrarquesca ${ }^{26}$, se convierte en expresión misma de lo espiritual y posible vía "anagógica" para el amante. Por su parte, el carácter idealista de los conceptos manejados por Michelangelo se ratifica al indicar que la belleza sensible no puede considerarse verdadera expresión de lo ideal sino solo a través de su mediación anímica, donde aquella se transforma; ya que, como señaló san Agustín, tras contemplar los cuerpos, la mente «imagines eorum convolvit, et rapit factas in semetipsa de semetipsa. Dat enim eis formandis quiddam substantiae suae» ( $D e$ Trinitate X, V, 30-32; Corpus Christianorum Series Latina L, 321; «envuelve las imágenes de ellos, y toma a las creadas en sí misma desde sí misma. Pues al formarlas les da algo de su substancia»). Ficino (2001: 154) indicó cómo, al interiorizarse, las formas son procesadas de un modo superior por la phantasía: "Quae enim singuli quinque sensus accipiunt singulatim, phantasia summatim discernit et aliquid excellentius» (Theologia platonica II, IX, 6; «En efecto, lo que reciben cada uno de los cinco sentidos de modo individual, la fantasía lo discierne de modo conjunto y en algo más excelente»), facultad superada a su vez en el proceso cognoscitivo por el intellectus. Hacia la más excelente esfera anímica apunta uno de los sonetos, donde el yo lírico pregunta al Amor:

Dimmi di grazia, Amor, se gli occhi mei veggono 'l ver della beltà c'aspiro, o s'io l'ho dentro allor che, dov'io miro, veggio scolpito el viso di costei. $(42,1-4)$

A lo cual el dios responde:

— La beltà che tu vedi è ben da quella, ma cresce poi c'a miglior loco sale, se per gli occhi mortali all'alma corre. $(42,9-11)$

La belleza, en efecto, proviene de la amada («da quella»), pero «crece después en mejor sitio», es decir, el alma contemplativa, como expone Mario Guiducci, «facendo nell' intelletto... uficio di seme» ${ }^{27}$, pues en efecto, para el neoplatonismo y según explicara Leone Ebreo (1929: [III], fol. 98r), el alma del amante se encuentra «ingravidata del seme di esso bello». Esta «semilla» puede, en el orbe anímico, realmente florecer en su naturaleza ideal, «crecer» cualitativamente en un proceso de «sublimación» interior, mostrándose como «cosa immortale» $(42,13)$; al modo de un poema de Sinesio de Cirene:

26 «Gentil mia donna, i’ veggio / nel mover de' vostr' occhi un dolce lume / che mi mostra la via ch' al ciel conduce» (LXXII, 1-3; Petrarca 1951: 105).

27 «Parimente in quel felicissimo stato avendo l'uomo copia di vagheggiare quella bellissima idea, al cui bel sembiante era stato formato, non gli fu uopo di terrena beltà; la quale, facendo nell' intelletto di lui uficio di seme, eccitasse la volontà ad amare e bramare quella sovrana e primiera, del cui benchè piccol raggio participando talora le cose create, ne ricevono il titolo e 'l vanto di Belle.» (Guiducci 1863: CXVI) 


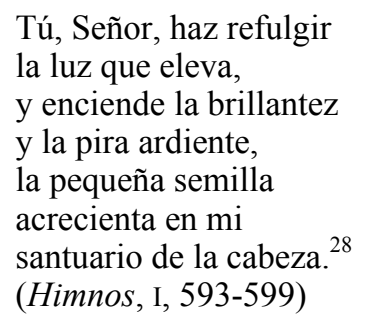

Hay un principio interior que, bajo el influjo de la luz de lo divino, puede desarrollarse para rendir el fruto de sus posibilidades transcendentales, ya como la ínsita "semilla" del alma, ya - como en la erótica renacentista - como la «belleza amada» inserta en el corazón. En cierto modo, se trata de un proceso que podría hacer pensar también en la dilatatio cordis de la que habla la teología cristiana ${ }^{29}$, al que ha aludido en otros poemas (como en el ya citado caso de "Che cosa è questo, Amore, / c'al core entra per gli occhi, / per poco spazio dentro par che cresca?»; 8, 9-11). En Colonna (2004: I, 438) aparecen, por cierto entremezclados, los tópicos de las "saetas" y las "semillas" de Amor: «Et cusi prima essa nel tenero core seminoe, dalle pongiente sagitte arato, gli amorosi incendii, piu noxio \& mortale semento, che non sparse Iasone, \& pegiore Annona». Por su parte, Leone Ebreo (1929: [III], fol. 152v) ha explicado con claridad el proceso de la alquimia anímica de las semillas imaginarias:

di quella persona amata l'immagine ne la mente de l'amante avviva con la sua bellezza quella bellezza divina latente, che è la medesima anima, et gli da attualità al modo che gli daria essa medesima bellezza divina esemplare, onde ella si fa divina, et cresce, et fassi maggiore in lei sua bellezza, quanto è maggiore la divina che l'humana [...]

Por vía de la belleza inherente al alma, la bella imagen exterior puede adquirir el ser en acto del exemplar divino y crecer cualitativamente, sumando belleza a la

28 Tal "semilla" se ubica aquí en la cabeza, lugar de la razón que, según la enseñanza platónica, gobierna «desde la acrópolis» (Timaeus 70a6, 90a2-b1; Respublica 560b7-8), la arx mentis físico-metafísica desde donde manda a las demás potencias, sometidas a ella o rebeldes; véase del propio Sinesio el tratado De insomniis (v, 136a), donde la misma metáfora de «la acrópolis» se aplica al phantastikòn pneûma como regente de los sentidos (cfr. Calvitii encomium XII, 76a).

${ }^{29}$ En ese caso, es «como tener a Dios en el corazón», según un comentario de Pedro Lombardo: «quasi jam habens in corde Dominum, de quo ante loquebatur, ex dilectione ei familiariter loquitur, in quo demonstratur cordis dilatatio» (Commenatrius in Psalmos davidicos IV, 1; Patrologia Latina CXCI, col. 84C). Se le adjudica tal poder al amor cristiano (dilatatio charitatis); al modo de este pasaje de Isaac de Stella: «amoris vero ac suavitatis, fervoris et hilaritatis ortus primi dici vespera, et mane secundi, id est delectatio quaedam, ac dilatatio cordis, et interna quaedam exsultatio et exhilaratio mentis») (Sermones XVII; Patrologia Latina CXCIV, col. 1478D). En un contexto erótico, valga el ejemplo de Colonna (2004: I, 369): «Onde io farcito di fructuoso amore nellaccenso pecto ampliato». 
belleza; solo por medio del alma del amante, la imagen recogida por los sentidos se convierte en vivo trasunto de la Idea.

\subsection{La escala ontológica}

Michelangelo, como «neoplatónico cristiano» y discípulo de Dante, ve en la experiencia erótica un plausible proceso de retorno a Dios, donde el furor amoroso despertado por la belleza mundana se convierte en «primer peldaño» de una escala:
Amore isveglia e desta e 'mpenna l'ale, né l'alto vol preschive al van furore; qual primo grado c'al suo creatore, di quel non sazia, l'alma ascende e sale. $(260,6-9)$

Se trata, por tanto, de un amor útil por dar alas al alma y no impedir, aun a su «vano furor», un vuelo más alto; pero por ello mismo no puede quedar fijo en la mujer, como "en gran medida desemejante" a esa pasión que sería indigna de un corazón "sabio y viril":

L' amor di quel ch'i' parlo in alto aspira;
donna è dissimil troppo; e mal conviensi
arder di quella al cor saggio e verile.
L'un tira al cielo, e l'altro in terra tira;
nell'alma l'un, l'altr'abita ne' sensi,
e l'arco tira a cose basse e vile. (260, 9-14)

El amor (la pasión) que lleva hacia la tierra corresponde solo a los sentidos (es, como ya decía Alberti, enemigo de un «ingegno libero e virile») ${ }^{30}$; el otro, aspira a lo celeste y habita «en el alma»; por ello la erótica tiene la posibilidad, emblematizada en el símil de la escalera, de hacer subir o bajar, en un agonismo que cifra ejemplarmente la célebre alegoría del carro del alma y sus dos corceles antagónicos (Phaedrus 246a-b). Así, según la división platónica de tres tipos de amor, la voz lírica reniega de la forma más baja de la corruptissima voluptas e incluso de su vertiente "media", que equilibra lo corporal y lo racional, y aspira a su

${ }^{30}$ En el De Amore (Epistola. A Paolo Codagnello): «Così me parse avere provato a te quanto chi era servo dell'amore, costui niente potea cosa alcuna degna o atta a uno ingegno libero e virile» (Alberti 1973: III, 249). Alberti deplora la «cura amatoria» como «pestifera» y «perniciosa» para los estudios, la hacienda y la fama de los nobles ingenios. Ciertamente, en el contexto festivo de un conocido poema atribuido al mismo Alberti (1960: II, 28 y 30), este puede encarecer «la dolce fiammetta» del amor, y decir que quien no participa de ella «è monco / d'ogni destro ingegno» $(3,64-65)$. Michelangelo por su parte participa, en cierta medida, de ambas posturas y adopta, en la tradición de la poesía dantesca y la lírica neoplatónica, el desprecio de la pasión sensual y la exaltación del amor espiritual. 
manifestación más alta: el divinus amor ${ }^{31}$. El sentido de fondo es explicado en la erótica del Symposium y su implícita epistrophé —Enneades I, 2, 4, 18-, el "retorno" hacia lo divino en un movimiento inverso a través de la escala ontológica, convertida, desde lo bajo, en ascensional, avanzando desde los cuerpos bellos al saber de la belleza absoluta:

Pues esto es entonces andar rectamente por los asuntos eróticos o ser conducido por otro, comenzando por estas cosas bellas [las del mundo] y a causa de aquella belleza [la ideal] ascender siempre, usándolas como escalones [epanabasmoi], de un cuerpo a dos y de dos a todos los cuerpos bellos, y de los cuerpos bellos a las bellas costumbres, y de las bellas costumbres a las bellas ciencias, y de las ciencias hasta ser cumplida aquella ciencia, que no es de otra cosa, sino ciencia de aquello mismo bello, y conozca al fin lo que es la belleza en sí misma. (Symposium 211b-d)

Con respecto al proceso creador del universo, de lo ideal a lo material, el amor permite una "reversión" de lo sensible a lo suprasensible (ello lo expone también, con base en el mismo pasaje del Symposium, Plotino: Enneades I, 3, 2). Eros, el "deseo apasionado" correspondería aquí a la órexis, el "apetito" que busca, según expuso Proclo, el bien sumo, «y hacia el que en primer lugar es el anhelo, hacia ello es el retorno», cuyo camino queda abierto desde lo fenoménico a partir de una vía relacional, "pues en efecto todo retorno se realizaría a través de la semejanza» (Institutio theologica, 31, 9-10; 32, 7-8); en este caso, la sympátheia que entreteje idealmente al cosmos posibilita que la belleza corpórea sea vista como una "imagen" de la belleza suma y que sirva así, a modo del hilo de Ariadna, de clave conductora para el alma, a través del laberinto de la materia, en su regreso a lo divino. Esta vía ascendente corresponde en el imaginario alegórico cristiano a la escala de Jacob veterotestamentaria ${ }^{32}$. Sugestiva es la prescripción de Nicolás de Cusa, que, empleando el mismo motivo, enlaza el descubrimiento de Dios con la naturaleza de la visión (en una línea que podría servir muy bien de glosa para la

${ }^{31}$ Según la exposición que ofrece Apuleyo: «Plato tres amores hoc genere dinumerat, quod sit unus diuinus cum incorrupta mente et uirtutis ratione conueniens, non paenitendus; alter degeneris animi et corruptissimae uoluptatis; tertius ex utroque permixtus, mediocris ingenii et cupidinis modicae» (De Platone et eius dogmate II, 14, 1-6).

32 «Quoniam igitur prius est ascendere quam descendere in scala Iacob, primum gradum ascensionis collocemus in imo ponendo totum istum mundum sensibilem nobis tanquam speculum per quod transeamus ad Deum opificem summum» (San Buenaventura, Itinerarium mentis in Deum I, 9). La alegoresis de la escala de Jacob, con implicaciones cosmológicas, morales y metafísicas fue ya desarrollada por Filón de Alejandría en su tratado De somniis (I, 133 y ss.); entre otras cosas, señaló su sentido simbólico de la organización jerárquica de las potencias anímicas del hombre, desde la sensación, como el «pie» que está en lo terrestre, hasta el más puro intelecto como la «cabeza» que se levanta al cielo (I, 146-147). En el Renacimiento, conocido es el pasaje del De hominis dignitate de Pico della Mirandolla (1942: 114 y 116) donde se utiliza la alegoría de la escala para representar también las potencias ascensionales del hombre. 
poesía miguelangelesca): «Oportet igitur, ut naturam sensibilis visionis ante oculum visionis intellectualis dilatemus et scalam ascensus ex ea fabricemus» (De quaerendo Deum 19, 15, 12-14 [en Flasch 1997: 117]; «Es preciso entonces que la naturaleza de la visión sensible dilatemos ante el ojo de la visión intelectual y a partir de ella fabriquemos la escala del ascenso»).

\section{ALEGORÍAS DEMIÚRGICAS}

\subsection{El corazón como lugar de las imágenes y de creación interior}

En la exposición idealista de Michelangelo, al corazón corresponde no solo ser el especialísimo receptáculo de la imagen del ser amado, sino de todas las formas bellas captadas por los ojos:

Passa per gli occhi al core in un momento qualunche obbietto di beltà lor sia [...]. $(276,1-2)$

Esto puede sin mucho trabajo remitirnos a otras formulaciones de la teoría artística del Renacimiento en parte afines, como la de Dürer (1893: 227) sobre el «secreto tesoro del corazón» («heimlich Schatz des Herzen»), que constituye el acervo imaginario con el que labora el artista y que corresponde a una versión «técnica» del tradicional thesaurus de la phantasía. Se trata por tanto de un conjunto que se desprende de su fuente sensible con la posibilidad de ser restablecido como memoria, cuya labor particular es comparada a la de pintar y esculpir dentro del corazón. Así, en las imágenes evocadas del hermano y el padre ya muertos:

La memoria 'l fratel pur mi dipigne,

e te sculpisce vivo in mezzo il core $[\ldots] .(86,13-14)$

De nuevo, a Platón se remonta la idea de la «estatua» formada de modo interior por el amante: «y como si aquel [el amado] fuese el propio dios, en sí mismo una especie de estatua construye y adorna» (Phaedrus 252d6-7); "scultura di tua immagine» (Leone Ebero 1929: [III], fol. 1v). Según esta antigua fórmula, la imagen es inscrita en el corazón (en Virgilio: «haerent infixi pectore vultus / verbaque»; Aeneis IV, 4-5) como repositorio de la imaginación y sede del sentimiento amoroso. En su carácter de «pintura interior» tiene una significativa exposición en un pasaje de Plutarco donde se compara a la impresión visual «normal» con una pintura «en agua», mientras que la permanencia de las figuras en el alma del amante semeja más bien la modalidad «al fuego» de la encáustica (Amatorius 759 C 3-9). Esta corresponde a la perdurable creación de la imagen de la amada en la imaginativa del amante, como la que realizan los pensieri di Amore al interior de Polífilo en la Hypnerotomachia de Colonna (2004: I, 283): 
Ma piu noxii, \& molto piu iniqua \& uexatrice cæde gli furaci et uagi pensieri experiua di questo ualoroso signore, optimi di tale materia solerti quæstori, \& dil quæsto aptissimi artifici ad fabriculare \& componere di foco \& di fiamme si dolce tormento, si uenerando idolo, si formoso simulachro, si præstante forma. Nella officina dilla imaginatiua \& solatiosamente fingere.

Por supuesto, Michelangelo tiene en este caso más a mano la metáfora recurrentemente usada por Petrarca (1951: 72):



Lo destacable en la poesía miguelangelesca es que esta metáfora es, de hecho, una bisagra conceptual-imaginaria en donde converge la temática erótica con la del arte en su dimensión interior.

\title{
3.2. El artista como demiurgo
}

De modo distintivo, los poemas de Michelangelo tocan a veces de manera central el tema de la labor artística, también en sintonía con las enseñanzas de la Academia. Así, el artista-demiurgo imita el modo creador de Dios, como expone el conocido soneto:

\author{
Se 'l mie rozzo martello i duri sassi \\ forma d'uman aspetto or questo or quello, \\ dal ministro che 'l guida, iscorge e tiello, \\ prendendo il moto, va con gli altrui passi. \\ Ma quel divin che in cielo alberga e stassi, \\ altri, e sé più, col propio andar fa bello; \\ e se nessun martel senza martello \\ si può far, da quel vivo ogni altro fassi. \\ E perché 'l colpo è di valor più pieno \\ quant'alza più se stesso alla fucina, \\ sopra 'l mie questo al ciel n'è gito a volo. \\ Onde a me non finito verrà meno,
}

${ }^{33}$ Véase Rime XCVI, 5-6; C, 12-13; CLV, 9-11 (Petrarca 1951: 135, 139 y 221). Y los antecedentes en Dante: «L'imagine di questa donna siede / su ne la mente ancora, / là 've la pose quei che fu sua guida / e non le pesa del mal ch'ella vede» (Rime XIII [LIX], 43-46); «Io non posso fuggir ch'ella non vegna / ne l'imagine mia, /se non come il pensier che la vi mena. / L'anima folle, che al suo mal s'ingegna, / com'ella è bella e ria, / così dipinge, e forma la sua pena» (Rime LIII [CXVI], 16-21 y ss.; Alighieri 1965, 64 y 207-208). 
s'or non gli dà la fabbrica divina

aiuto a farlo, c'al mondo era solo. (46)

Guasti (Buonarroti 1863: 226, n. 1) y luego Frey (Buonarroti 1897: 386) indicaron la «referencia imposible» - según Garin (1966: 525) — de este poema al Crátilo de Platón, donde se adscribe la pertinencia de cada instrumento (órganon) a la forma (to eîdos) que propiamente lo produce (389b-c), y que, en el caso del soneto, se remonta ontoteológicamente a su origen divino. Con buena probabilidad, según las observaciones de Girardi (Buonarroti 1960: 199) secundadas por Garin, Michelangelo tuvo en cuenta unas estrofas de Dante:

Lo moto e la virtù d'i santi giri, come dal fabbro l'arte del martello, da' beati motor convien che spiri; e 'l ciel cui tanti lumi fanno bello, de la mente profonda che lui volve prende l'image e fassene suggello.

(Paradiso II, 127-132 [Alighieri 1967: IV, 34-35])

El movimiento del cielo es causado por las fuerzas espirituales (beati), del mismo modo en que el artífice es la causa del arte que dirige el martillo; y la belleza estelar del cielo octavo, el firmamento, adopta la imagen de la «mente profonda», angélica, como del sello que la marca (repitiendo otro símil platónico), y que ejerce después su influjo sobre el mundo sublunar ${ }^{34}$. Dante canta el orden jerárquico del cosmos como un sistema ontoteológico descendente, donde los orbes superiores ejercen su influjo sobre los inferiores (como en su comentario dice Benvenuto da Imola [1887: IV, 358]: «quia more sigilli imprimit in inferiora»), y lo inteligible determina las manifestaciones de lo sensible. No resulta, quizás, demasiado aventurado conjeturar que Dante haya establecido la comparación entre el martillo del artesano con el cielo a partir de una asociación como la explicada en las Derivationes de Ugguccione da Pisa (2004: II, 209-210) sobre el verbo latino «celo» [«caelo»], «idest sculpere, pingere, et est in alia significatione contrarium ad revelare» («esto es esculpir, pintar, y es en otra significación contrario a revelar»), donde se propone como derivado suyo celum [caelum], 'cielo': «Item a celo -las hoc celum -li, quia celat nos secreta, vel a celo -las pro sculpere, quia sculptum est et insignitum variis stellis» ${ }^{35}$ («También de celo, -las, es celum -li, porque nos

${ }^{34}$ En el Ottimo commento (Torri 1829: III, 46), se realza el paralelismo entre el maestroel martillo-la obra y Dios-el cielo-las cosas inferiores: «Poi e' dà uno esemplo materiale nell'opera fabrile, dove sono tre cose, il maestro, il martello, e l'opera. Nel mondo Iddio è il maestro, li Cieli è il martello, le cose di sotto l'opera» (Paradiso II, 124).

${ }^{35}$ La hipótesis etimológica la transmite Varrón: «Caelum dictum scribit Aelius, quod est caelatum aut contrario nomine celatum, quod apertum est; [non] male, quod posteriora multo potius a caelo quam caelum a caelando [aut celando]. Sed non minus illud alterum de celando ab eo potuit dici, quod interdiu celatur, quam quod noctu non celatur» (De lingua 
oculta las cosas secretas, o de celo, -las por esculpir, porque está esculpido y adornado con varias estrellas»). La segunda semejanza de Dante, establecida con base en el suggello, resulta coherente con la entrada de Uguccione en tanto que el cielo se encuentra insignitum, 'marcado' por las estrellas creadas por el Artífice del cosmos.

No es imposible que tal vínculo «etimológico» y semántico gravitase también en la mente de Michelangelo, en cuyo poema la elevación de la herramienta hace explícita de otro modo esta relación ${ }^{36}$. Sea como fuere, la visión hipostática que informa las líneas del Paradiso tiene también lugar en el soneto. El martillo del artífice sigue, en efecto, la voluntad del artista en su accionar, que lo torna capaz de reproducir la forma del hombre o de las diversas cosas del mundo. Pero antes y por encima de él se encuentra el Martillo divino, que embellece con sus obras la naturaleza y a sí mismo; es este el modelo necesario de aquel otro («nessun martel senza martello / si può far»), lo que, se trate o no de una alusión al Crátilo, evidencia el influjo de las concepciones platónicas. A su vez, el recto operar del artista deviene realmente de la inspiración; su voluntad superior queda materialmente manifiesta a través del movimiento ascendente del instrumento, «hacia el cielo», en el trabajo del escultor, que da su golpe descendiendo de esa altura física-metafísica, y cuya eficacia verdadera radica en lograr que la voluntad creadora que lo guíe provenga en realidad «de arriba». Solo a través de la «ayuda» del paradigma ideal de la creación cósmica puede alcanzarse la excelencia del arte; y, por vía de lo divino, será capaz de superar a la misma naturaleza:

A la bell'arte che, se dal ciel seco

ciascun la porta, vince la natura,

quantunche sé ben prema in ogni loco [...] $(97,9-11)$

A la luz de la gradación ontológica, el alma del artista puede convertirse en un agente mediador de la forma eterna que logre, por encima de la naturaleza, su expresión en el orden de la materia.

Latina libri, v, 18; 8). No dejó de utilizarla Varchi (1960: 50-51): «E quegli che dicono che la macchina del mondo è una nobile e gran pittura, avrebbero detto più veramente, secondo ch'io penso e come può vedere ciascuno, se avessero detto scultura, come ne dimostra appresso i Latini il nome del cielo, che vuol dire "scolpito" e non "dipinto"».

36 Piénsese como un eventual estímulo añadido, junto al ya mencionado, para la comparación entre el cielo y el martillo del artesano, la homonimia de caelum como 'cielo' y 'cincel' (caelum / caedere, 'tallar, esculpir, grabar'). El sentido de esta segunda voz, que no pervivió en las lenguas romances, era accesible a través de una fuente tan difundida como san Isidoro: "Caelata vasa argentea vel aurea sunt, signis eminentioribus intus extravae expressa, a caelo vocata, quod est genus ferramenti, quem vulgo cilionem vocant» (Etymologiae XX, IV, 7). 


\subsection{La plasmación del concetto intelectual interior}

Uno de los más conocidos poemas de Michelangelo, comentado por Benedetto Varchi, es emblemático de la estética del artista:

Non ha l'ottimo artista alcun concetto c'un marmo solo in sé non circonscriva col suo superchio, e solo a quello arriva la man che ubbidisce all'intelletto.

Il mal ch'io fuggo, e 'l ben ch'io mi prometto, in te, donna leggiadra, altera e diva, tal si nasconde; e perch'io più non viva, contraria ho l'arte al disïato effetto.

Amor dunque non ha, né tua beltate o durezza o fortuna o gran disdegno, del mio mal colpa, o mio destino o sorte;

se dentro del tuo cor morte e pietate porti in un tempo, e che 'l mio basso ingegno non sappia, ardendo, trarne altro che morte. (151)

Cabe resaltar la aparición del término concetto, que fue explicado por Varchi (1863: XCIV) del siguiente modo:

In questo luogo si piglia Concetto dal nostro Poeta per quello che dicemmo di sopra chiamarsi da' Greci idea, da' Latini exemplar, da noi modello; ciò è per quella forma o immagine, detta da alcuni intenzione, che avemo dentro nella fantasia, di tutto quello che intendiamo di volere o fare o dire; la quale se bene è spiritale, onde non pare che possa operare cosa alcuna a chi non intende, è però cagione efficiente di tutto quello che si dice o fa. Onde diceva il Filosofo nel settimo libro della prima Filosofia: Forma agens respectu lecti est in anima artificis $[\ldots]$

Panofsky ha resaltado el sesgo aristotélico de esta exposición, explicado por Varchi a través de una conveniente referencia al estagirita ${ }^{37}$. De acuerdo con

${ }^{37}$ Ciertamente, lo enseñado por el estagirita resulta propicio para comentar el poema, como apuntó Varchi (1863: xCV y XCII), en la medida en que aporta un ejemplo muy próximo al contexto miguelangelesco, en el aserto del filósofo sobre que «In lapide est forma Mercurii in potentia», implicando "che d' un marmo solo si possono cavare tutte le figure». Para ilustrar el ser en potencia (dynámei), Aristóteles afirmó: «y en efecto, decimos que hay un Hermes en la piedra» (Metaphysica V, 8, 1017b6-7); y, recurriendo a la misma imagen: "pues decimos en potencia al modo en que es en la madera un Hermes y en la línea entera la mitad, porque podría ser separada» (IX, 6, 1048a 32-33), asumiéndose con ello, según indica su comentarista Alejandro de Afrodisias, «que es posible crear un Hermes de 
Panofsky, el poema de Michelangelo, al no indicar un origen trascendental del concetto ni su «caída» en la materia, se mantiene dentro de las lindes de las concepciones de Aristóteles; incluso, especula un posible «celo neoplatónico» por parte del maestro florentino en el uso de concetto para evitar un empleo inexacto de la más alta $i_{d e a^{38}}$. Esto acaso pueda entenderse de un modo distinto, como una restricción antes léxica que de contenido, en la medida en que el helenismo idea es palabra poco usada en la poesía italiana (y en otras lenguas modernas) ${ }^{39}$. Cabe asimismo aclarar que la voz concetto, al menos en el ámbito de la poesía petrarquesca, no tiene por necesidad un sesgo aristotélico al modo en que Panofsky pretende. De hecho, para ilustrar la palabra, Varchi cita el inicio de un soneto de Petrarca, que se refiere al cuadro de Laura realizado por Simone Martini:

Quando giunse a Simon l' alto concetto

ch' a mio nome gli pose in man lo stile [...].

(LXXVIII, 1-2; Petrarca 1951: 116)

Este «alto concetto», de acuerdo con el soneto anterior del propio Petrarca, correspondería a la visión transcendental de una "idea", al modo de la atribuida por la tradición a Fidias:

ma certo il mio Simon fu in paradiso, onde questa gentil Donna si parte; ivi la vide e la ritrasse in carte, per far fede qua giù del suo bel viso. (LXXVII, 5-8; Petrarca 1951: 115)

ella ["en una piedra no trabajada"]» (In Aristotelis Metaphysica commentaria, 372, 23-24), dicho que amonedará un proverbio para señalar por alegoría los límites de la potencialidad de los hombres y sus talentos, en particular, según Erasmo (1514, fol. 153r), figurando a los indocilia ingenia: «Non e quouis ligno Mercurius fiat» (II, 449 [V, 47]; «no de cualquier madero se hace un Mercurio»). El concepto lo utilizó también Leone Ebreo (1929: [III], fol. $68 \mathrm{v}$ ): «Ne le cose artificiali vedrai un'legno rozo à chi manca la forma, et belleza d'una statua d'Apolline, niente di manco è in potenzia à quella».

38 «...und nicht ohne Absicht dürfte er den Terminus "Concetto" dem bei andern gleichzeitigen Autoren schon einigermaßen abgegriffenen, dagegen gerade für ihn, als wirklichen Kenner des Neuplatonismus, im Sinne einer transzendenten Auffassung verpflichtenden Ausdruck "Idea" vorgezogen haben: Michelangelos künstlerische "Gedanken" brauchten sich ihres göttlichen Ursprungs und ihrer übernatürlichen Schönheit weder zu rühmen, noch durch die Berufung darauf sich zu rechtfertigen» (Panofsky 1960: 68).

${ }^{39}$ Ciertamente, es notorio que hay ya una incidencia de la palabra en la Commedia: "Ciò che non more e ciò che può morire / non è se non splendor di quella idea / che partorisce, amando, il nostro Sire» (Paradiso XIII, 52-54; Alighieri 1967: IV, 210). También hay otro ejemplo en la poesía de Petrarca, en este caso referido a la belleza de Laura: «In qual parte del ciel, in quale idea / era l'esempio onde natura tolse / quel bel viso leggiadro, in ch'ella volse / mostrar qua giù quanto lassù potea?» (CLIX, 1-4; Petrarca 1951: 225). 
Es decir, refiriendo la observación directa del «alma eterna» de Laura, cuyo «concetto» corresponde también a la «idea» (Petrarca 1951: 225) de la que habla en otro de sus sonetos (CLIX, 1), de modo tal que, en efecto, no habría diferencia mayor de significado entre estos términos, según ha indicado el propio Varchi ${ }^{40}$.

Ahora bien, el poema propone que el surgimiento del "concetto" corresponde a aquello interiormente visto por el artista, cuya mano «obedece al intelecto». Esto subraya la prevalencia de lo "mental" sobre lo práxico para la escultura (Filarete señaló del escultor «che bisogna che lavori alla mente», XXIII), asumido también, por supuesto, para la pintura, en tanto «che si dipinge col ciervello et non con le mani» (Buonarroti 1976: 187). Por su parte, la lectura de Varchi (1863: XCVIII) trata de explicar esto como conceptualmente correspondiente con el intelletto passibile «e questo non è altro che la fantasia, o vero immaginazione», de acuerdo con los comentarios tardíos de Juan Filópono. Tal interpretación establece como base el supuesto de que la nominación intelletto en el soneto tiene como real sentido fantasia o immaginazione. Este intento radica, conjeturablemente, en el deseo del erudito de «validar» el uso de la palabra en el contexto de la creación artística para Clements, una «aportación» léxico-conceptual miguelangelesca en este campo $^{41}$ - , que resultaba, en términos filosóficos, cuestionable - lejos por cierto de un ortodoxo «celo neoplatónico» como el que propuso Panofsky para explicar la omisión de «idea»- y que obliga a una justificación conceptual (para la que Varchi utilizará, como es común en el período, argumentos respaldados en una cierta auctoritas que no dejan de ser, por sí mismos, discutibles), en la misma línea semántica aunque en sentido inverso a la que Mazzoni expondrá sobre «l'alta fantasia» dantesca como virtual equivalente de intelletto ${ }^{42}$.

Por lo tanto, resulta aventurado establecer con precisión una intencionalidad calificable de "aristotélica" en el poema de Michelangelo, pues, leído por sí mismo y sin contextualizarlo dentro del resto de la producción lírica del artista (y su más

${ }^{40}$ Valga como ejemplo similar del uso de concetto el que presenta la versión de un texto de Poussin que ofrece Bellori: «Quanto al concetto, questo è mero parto della mente, che si và affaticando intorno le cose, quale fù il concetto di Homero e di Fidia nel Gioue Olimpio...» (Bellori 1672: 460).

${ }_{41}$ Buonarroti sería «the first of the theorists on art to utilise the word intelletto» (Clements 1961: 403). Aunque la voz aparece ya utilizada por Boccaccio (intelletto: Decameron, Giornata VI, novella 5, 6; Boccaccio 1999: 524-525) o Manuel Chrysoloras (noûs: Epistola III; Patrologia Graeca CLXVI, col. 57) para designar los procesos de creación-recepción de las obras pictóricas, y, en la literatura artística, ya fue empleada por el propio Cennino Cennini.

42 «Dico adunque, che Dante anchora, conoscendo che la voce Phantasia, era solita a prendersi per potenza sensitiua, e volendo egli prenderla per potenza intellettiua, si ageuolò la via coll'Epitheto d'Alta, di maniera che quell'aggiunto fà prendere la voce Phantasia, per intelletto» (I, LII; Mazzoni 1587: 161). ${ }^{43}$ «As perceived by Michelangelo, likewise brought out in his sonnets, the ideal forms brought to light by the artist correspond to forms primordially implanted by God in the artist's mind» (Brann 2002: 269). 
clara inclinación neoplatónica), no puede determinarse con exactitud a lo que se alude con concetto, más allá de lo que apuntan las indicaciones generalizadoras del comentarista (quien, a buen seguro, "evitó" establecer la ecuación concetto = Idea por las propias inclinaciones de su pensamiento y/o el problema metafísico que tal equipolencia supone). Así, nada impide en rigor que los poemas puedan leerse también bajo una óptica neoplatónica, donde los "concetti" - como supone Brann - corresponderían a "formas innatas" de origen divino ${ }^{43}$. Recuérdese que Michelangelo ha declarado de manera abierta y categórica, en un madrigal, que goza del exemplum innato de la belleza que le sirve de "luz" y "espejo" para sus labores artísticas:

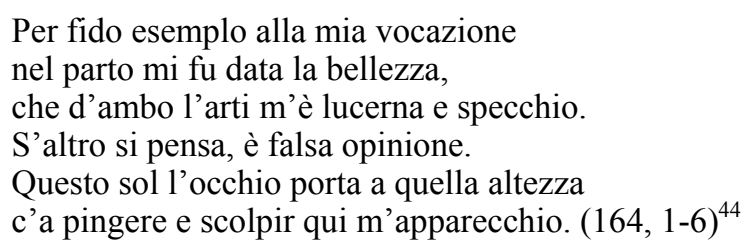

Añádase, en abono de tal ambigüedad, el hecho de que Varchi ha insertado tal interpretación de corte aristotélico dentro de una teleología ontológica propia a la de la teoría erótica de Platón y sus seguidores - cuyos tópicos indagó el erudito en obras próximas, como las cuatro lecciones leídas en la Academia Fiorentina Sopra alcune quistioni d'amore-, donde el Amor es la fuerza ascensional del espíritu hacia su fuente eterna ${ }^{45}$.

\subsection{La «substracción» de la materia}

En el soneto comentado por Varchi aparece expuesta la idea, célebremente relacionada con el nombre de Michelangelo, de la aphaíresis ('substracción' o 'remoción'); es decir: el operar del escultor se limita a retirar el material 'excedente' (soverchio) para que emerja la forma ínsita en él. Cabe recordar que se trata de un término ya codificado en la Antigüedad en el ámbito del arte, como muestra Dión Crisóstomo, al comentar las diversas modalidades en la plástica como expresión de lo divino, sea ya por el dibujo o la pintura, «ya por tallas en piedra o

44 Pero, como destaca Folliero-Metz (1996: 467 y 470), la solución miguelangelesca sobre el problema de la fuente y sentido del arte no se reduce a una precondición innata como don «gratuito», sino que también se entiende, dinámicamente, como fundado en el «cor ch'è più capace» $\mathrm{y}$ fruto de una búsqueda constante y la asunción sostenida $\mathrm{y}$ consciente de su «destino existencial» como saggio (poemas 273 y 241).

45 «...mi potrebbe alcuno dimandare, quale è quello strumento che n'ha dato la natura, mediante il quale possiamo ridurre a l'atto questa potenza, ciò è salire al cielo colla terrena soma, e divenire, d'uomini, dii. Alla costui e dotta dimanda e ragionevole si risponde, che questo strumento (oltra le scienze) senza alcun dubbio è l'Amore» (Varchi 1863: LXXXVI). 
trabajos de imágenes en madera, del arte que remueve poco a poco [aphairoúsēs] lo superfluo, hasta que deja libre la propia forma que se manifiesta) (Orationes XII, XLIV, 8-10). Es un concepto nada extraño a la teoría del arte renacentista - presente ya en el De statua de Alberti ${ }^{46}$-, pero, como bien ha señalado Panofsky (1960: 65), a través de Michelangelo la idea de la aphairesis escultórica «den gleichnishaftmoralischen Sinn zurückgibt, den er bei Plotin und im späteren Neuplatonismus besessen hatte» ${ }^{47}$. En efecto, el procedimiento técnico propio de la escultura, que obra «per forza di levare» ${ }^{48}$, se ahonda en su sentido metafísico enriqueciendo su vertiente moral. De cierto, en el ámbito de la filosofía es una palabra que se vincula de varios modos con el platonismo, como por ejemplo muestra Plutarco comentando la teoría de las Ideas de Platón, quien en su sistema pedagógico «induce a la inteligencia de las formas por remoción [ex aphairéseos] y recorte del cuerpo» (Platonicae quaestiones 1001E8-F1). De manera notable, la acción de quitar lo superfluo para liberar la imagen de una estatua fue ya utilizada, como metáfora moral, por Plotino:

¿Cómo puedes entonces mirar qué clase de belleza tiene el alma buena? Retírate en ti mismo y observa. Y si todavía no te miras bello, al modo en que el creador de una estatua, quien debe generar belleza, por una parte quitó, por otra retiró, por otra dejó pulido o limpio, hasta que sacó a luz un bello rostro en la estatua, así también tú quita todo lo superfluo y corrige todo lo torcido, todo lo obscuro trabaja limpiándolo para que sea brillante y no ceses de «construir» tu propia «estatua», hasta que brille en ti el esplendor de la virtud diviniforme, hasta que mires «que la prudencia se ha asentado en el santo trono [Phaedrus, 252d y 254b].» (Enneades, I, 6, 9, 6-15)

Una alegoría muy semejante es aplicada por el propio Plotino respecto de las idéai, que yacen en el interior del alma como 'estatuas' — agálmata - que deben ser limpiadas de herrumbre para volver a resplandecer: «Pues seguramente no es corriendo fuera por alguna parte que el alma "contempla la templanza" y "la justicia" [Phaedrus 247d5-6], sino ella misma consigo en la introspección de sí misma y de lo que era antes, viéndolas a modo de estatuas que se hallan en sí misma que, como si se hubieran tenido cubiertas de herrumbre por el tiempo, se han vuelto limpias» (Enneades IV, 7, 10, 42-47). Estas concepciones aparecen en varios contextos en la tradición filosófico-mística de los neoplatónicos; así —sin el símil

${ }^{46}$ Se perfila como de las dos modalidades en la creación de estatuas, frente a la de los «fictores» que trabajan «cum additamentis»: «Alii solum detrahentes veluti qui superflua discutiendo quaesitam hominis figuram intra marmoris glebam inditam atque absconditam producunt in lucem» (De statua 2; Alberti 2000: 142 y 144).

${ }^{47}$ «Restituyó el sentido alegórico-moral que había poseído con Plotino y en el tardío Neoplatonismo».

${ }^{48}$ Tal es la famosa expresión usada por Michelangelo, al contrastar a la escultura con la pintura (a la que es propio obrar «per via di porre»), en su carta a Varchi (Buonarroti 1998: 84). Sobre los aspectos teórico-técnicos de la integridad formal-conceptual de la obra en un solo bloque de mármol, véase Turner (2007). 
del escultor- en Proclo, al señalar la necesaria labor del alma: «a través de la remoción [aphairesis] de todas las cosas después de él [el Bien...] puesto que es necesario separar la idea del Bien de todas ellas» (In Rem publicam commentarii I, 280-281). La «idea» es, justamente, el meollo espiritual que debe ser liberado de sus ataduras sensibles a través de la negación total de estas; y aun el mismo intelecto en el hombre es comparado con una "estatua", cuando Proclo afirma: «Que el intelecto en nosotros es dionisíaco y verdaderamente estatua de Dioniso» (In Cratylum CXXXIII, 1-2). El tópico pasó al ámbito teológico del cristianismo por medio del muy difundido texto de Pseudo-Dionisio el Areopagita, cuando, en su gran exposición sobre la vía apofática, se dispone a:

cantar a la suprasubstancia suprasubstancialmente a través de la remoción [aphaíresis] de todos los seres, al modo de quienes hacen una estatua ingénita quitando todos los obstáculos que cubren a la apariencia pura en lo oculto, y de ello mismo por la sola remoción queda fuera la esplendente belleza. (De mysthica theologia II, 145, 4-7) ${ }^{49}$

Como puede verse, la imagen es pasible de ser trasladada del micro al macrocosmos, ya refiriendo, al modo de Plotino - y de Michelangelo-, una labor sobre el propio ser individual; ya, según sugiere el Pseudo-Dionisio, implicando una exposición ontoteológica que aspira a mostrar, a través de una dialéctica negativa, el fundamento oculto de todas las cosas. Un milenio más tarde, en la búsqueda hermética de esas arcanas relaciones, Giordano Bruno incluirá entre sus sellos imaginarios al antiguo Fidias como modélico formator, quien operaba también por subtractio y puede ser válida representación — como el pintor Zeuxis- de la phantasía ${ }^{50}$.

49 Según la glosa de Juan Escoto Eriúgena: «Deum cognoscere et videre superintellectualiter, per remotionem videlicet intellectualis cognitionis, cum ipse Deus visu intellectuali nullatenus attingatur. Etiam precamur, nos laudare posse supersubstantialem supersubstantialiter, id est, Deum, qui excedit omnem substantiam et omne ens, per ablationem omnium existentium, sicut est videre in artificibus, qui aliquam fabricant similitudinem de aliqua inanimata materia, qui sculpendo et incidendo removent exteriores partes materiae grossiores, qui occultant et cooperiunt, ne videri possit illa pura imago, quae naturaliter et potentialiter est interius, et per solam talium offendiculorum remotionem sine alio additamento manifestatur in propria specie ipsius imaginis pulchritudo, quae prius latebat in occulto» (Expositiones seu glossae in Mysticam theologiam Sancto Dionysii II, 1; Patrologia Latina CXXII, col. 276B-C).

${ }^{50}$ «Est etiam Phidias formator, ut quae pictor velut ex aliis exemplariter educit, et ubi velut super alienis delineamentis elaborans invenitur, ita ibique statuarius Phidias vel quasi formatione quadam e cera effingat, vel quasi additione pluriumque lapillorum ordinatione construat, vel quasi subtractione incultum informemque lapidem figurandum sculpat. // Phantasia, quam Zeuxim Pictoremque appellavimus, eandem non iniuria Phidiae nomine in proposito intitulabimus» (Triginta sigillorum explicatio, «Phidiae, qui tertiusdecem est sigillus, explicatio»; Bruno 1890: II, II, 135). 
De cierto, el retorno del tópico al ámbito de la erótica "recupera" el sentido original que el símil tenía en Platón del amante como artista interior de una imagen divina (Phaedrus 252d6-7), pero en una inextricable fusión con su significado artístico. Así, en otro soneto (84: Sì come nella penna e nell'inchiostro...) el poeta ha incluido además a la escritura como algo ínsito al material, a la pluma y la tinta, en este caso, donde yacen latentes los tres estilos retóricos. También las idéai (entendidas al modo de Hermógenes como «las formas del estilo») yacen «en potencia» en los materiales de la escritura. Según el despliegue conceptual del soneto, la interioridad del otro, en sí misma espiritual, se convierte en la materia reflejante del proceso anímico del yo lírico, donde este - como en el acto creadorsolo es capaz de encontrar algo «propio a sí mismo y semejante».

En los sonetos, es el amante, al modo del escultor, quien es capaz de extraer "muerte" o "piedad" del corazón del sujeto amado o "dolor y acerbas penas». Inversamente, en un madrigal, es ella quien "esculpe" al amante:

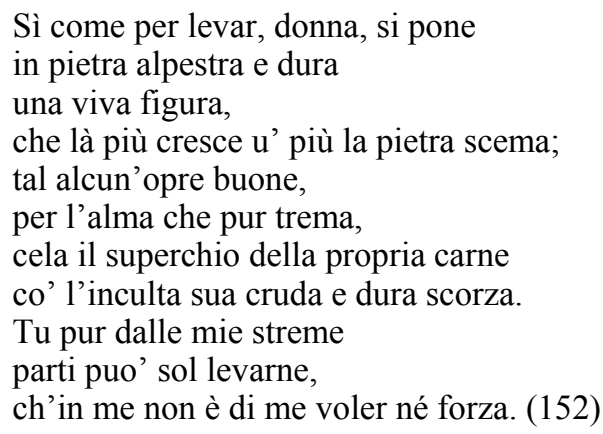

También en estos textos se insiste en la dualidad de lo espiritual y lo material, «immortal forma» $\mathrm{y}$ «carcer terreno» $(106,2)$, según el notorio tópico de índole órfico-platónica (con una cualidad conflictiva que en la escultórica refleja la serie de los Prigioni). ${ }^{51}$ Como es sabido, al comentar en el Crátilo (400c) el supuesto nexo "etimológico" entre sôma ('cuerpo') y sêma ('tumba'), Sócrates sugiere que el alma tiene a aquel como una "envoltura» que es «imagen de una prisión»; y el camino del «amante del aprender» es inexcusablemente el separar el alma de su vehículo para que more en sí misma «liberada como de ataduras del cuerpo» (Phaedo 67d1-2); es la Idea misma la que queda después de retirar la materia, de acuerdo con Ficino (1576: II, 1576):

${ }^{51}$ Según apuntaba De Tolnay (1954: IV, 61), esos «shapeless giants [...] seem scarcely to have emerged from the original matter». Sobre el tema del cautiverio, Parker (2010: 87-115) apunta en las cartas (aunque se trate de un contexto enunciativo distinto) matices diferentes que «desestabilizan» la visión neoplatónica y petrarquesca al respecto. Otros aspectos estudia Ruvoldt (2012). 
Forma uero in corpore formoso ita suae similis est ideae, sicut \& figura aedificii in materia similis exemplari in architecti mente, $\&$ ratio in uoce orationi, quae est in animo similis, itaque si homini materiam quidem detraxeris, formam uero reliqueris, haec ipsa quae tibi reliqua est forma, illa ipsa est idea, ad quam est homo formatus. (In Plotinum. In librum de pulchritudine commentarius, III)

[En verdad la forma en el cuerpo hermoso es de tal manera semejante a su idea, como la figura del edificio en la materia es semejante al modelo en la mente del arquitecto, y la razón en la voz semejante a la oración que está en el alma; por consiguiente, si de cierto arrancaras la materia al hombre, en verdad quedaría la forma, esta misma forma que para ti fue liberada, ella misma es la idea, según la cual el hombre fue formado]

Encontramos conceptos semejantes en Leone Ebreo (1929: [III], fol. 106r-v) para explicar el origen ideal de las Formas, cuya puridad se obtiene teóricamente al levare la materia que imperfectamente las retiene, en un proceso donde la creación divina se refleja en la humana:

le forme artifitiali derivano da la mente de l'artifice humano, ne la qual' prima esisteno maggior' perfettione e belleza, che nel corpo bellamente artifitiato, et cosi come levando per consideratione del bello artifitiato la corporentia non resta altro che l'Idea, la quale è in mente de l'artifice, cosi levando la materia de belli naturali, restano solamente le forme Ideali preesistenti ne l'intelletto primo, et da lui ne l'anima del Mondo.

En el poema de Michelangelo, la «recuperación» del alma se ve reconducida al terreno de la erótica, donde tal «envoltura» o «atadura» es la «cruda e dura scorza» de la carne, la «corteza» o «cobertura» material del hombre, donde yacen ocultas «alcun' opre buone», propias al alma, que pueden ser rescatadas por la «donna» de esa ruda materialidad externa, donde esta se mantiene como agencia espiritualizadora y potencialmente salvífica, fusionada en ello, si se quiere, con elementos del culto mariano y sus derivaciones corteses donde la mujer funge de advocatus del devoto frente a lo transcendente. Puede remitirnos también al Symposium platónico y la comparación que hace Alcibíades entre Sócrates y los silenos y la figura de Marsias, que muestran por fuera un talante rudo, pero que cuando «es descubierto» (216e6) revela en su interior áureas estatuillas divinas; las "obras buenas" son también esas estatuas interiores reveladas por la amada convertida en escultora espiritual.

\subsection{La visión sacrificial del cuerpo}

La severa visión de Michelangelo respecto del cuerpo como cobertura animal del alma se expresa, desde otra perspectiva, en un soneto dedicado probablemente a Cavalieri $^{52}$. El punto de comparación para la voz lírica es el gusano de seda, que

52 En los textos a Cavalieri es palmario el influjo de la teoría neoplatónica (Ficino, Diacceto), reflejado en los varios dibujos contemporáneos dedicados a él (ca. 1533: Ganimede, Tizio, Fetonte además de Il Sogno); como confirma Van den Doel (2008: 187- 
justifica su existencia a través del don de su substancia filamentosa, que sirve para vestir, con su muerte, al hombre:

\author{
D’altrui pietoso e sol di sé spietato \\ nasce un vil bruto, che con pena e doglia \\ l'altrui man veste e la suo scorza spoglia \\ e sol per morte si può dir ben nato. \\ Così volesse al mie signor mie fato \\ vestir suo viva di mie morte spoglia, \\ che, come serpe al sasso si discoglia, \\ pur per morte potria cangiar mie stato. \\ O fussi sol la mie l'irsuta pelle \\ che, del suo pel contesta, fa tal gonna \\ che con ventura stringe sì bel seno [...]. (94, 1-11)
}

La propia «hirsuta piel» se ofrece como devota ofrenda, que tratada en modo literal a manera de una «vestidura», adquiere el sentido de la animalidad sacrificada del hombre para convertirse en trofeo externo de un ser superior, que la justifica de un modo más alto. El referente mitológico del poema es, en efecto, el desollamiento de Marsias, según ha indicado Edgar Wind (1968: 188), vinculado asimismo con el «apóstol desollado» (lo Apostolo scorticato), San Bartolomé, que figura en el Giudizio Finale a modo de «an agonized self-portrait». El arte de madurez de Michelangelo apunta tensamente al sacrificio final de la forma exterior en aras de su contenido más profundo; muestra, por ello, la vía autocancelante de lo alegórico, tradicionalmente vinculado con la revelación de un sentido oculto a partir del despojamiento de la «cobertura», «corteza» o «vestidura» que lo encubre ${ }^{53}$, del

188 y 200): «De gedichten die Michelangelo voor Tommaso schreef, getuigen ook van Platoonse opvattingen over de liefde... Een (Neo-)Platoonse of Ficiniaanse context van de Droom-tekening is aannemelijk, evenals zoals zal blijken, van de andere presentatietekeningen».

${ }^{53}$ Es una idea constante en la tradición alegórica medieval, donde se utilizaron términos como velamen, involucrum, integumentum, cortex, incluso putamen ('desechos', a modo de cáscaras, cortezas u hojarasca), etcétera, donde la "letra" externa supone algo necesario para la manifestación del sentido pero inexcusablemente "removible" para acceder a la esencia de su contenido. Valga como ejemplo esta declaración de Dante sobre el indispensable saber del poeta, quien debe ser capaz de "desnudar" sus palabras para mostrar el real significado que esconden: «[...] però che grande vergogna sarebbe a colui che rimasse cose sotto vesta di figura o di colore rettorico, e poscia domandato non sapesse denudare le sue parole da cotale vesta, in guisa che avessero verace intendimento» (Vita nova, XVI [XXV], 10; Alighieri 1996: 155). En las Vite, Vasari (1986: II, 912) señala el hábito de Michelangelo de «encubrir» su discurso y sugerirse en él a menudo un «doble sentido»: «e stato nel suo dire molto coperto et ambiguo, avendo le cose sue quasi due sensi». Asimismo, como es sabido, Dolce (1960: 190) recogió en su Dialogo la fama sobre el carácter alegórico de su obra, 
modo en que, en el ámbito de la erótica neoplatónica, señala a la propia allegoría como un modelo hermenéutico que coparticipa con la phantasía como esfera epistemológica y ontológica que hace no solo posible el acto comprensor en el orden del mundo, sino que ilumina el nodus entre lo visible y lo invisible que nutre al tiempo que marca el límite insalvable del ser-hombre como «compuesto» de espíritu y carne reproducido en la creación artística.

En su maestro Dante aparece ya el motivo de Marsias convertido en símbolo de la transfiguración espiritual de la poesía:

O buono Appollo, a l'ultimo lavoro

fammi del tuo valor sì fatto vaso, come dimandi a dar l'amato alloro...

Entra nel petto mio, e spira tue sì come quando Marsïa traesti de la vagina de le membra sue. (Paradiso I, 13-15, 19-21; Alighieri 1967, IV, 4-5)

No es extraño que, en el comentario de Landino (2001: IV, 1567-1570), el pasaje aparezca explicado a la luz del furor divinus (buena muestra del modo en que Dante le era accesible a Michelangelo, también a través de tamices neoplatónicos). Ello implica, como en el caso de los sonetos sobre la «escultura interior», un proceso de kátharsis espiritual que reviste el triunfo de una esfera más alta del ser, implicando asimismo la muerte del plano inferior (aunque no deje de suponer, por otro lado, el nuevo revestimiento de la subtilitas de la phantasía poética ${ }^{54}$. La muerte aparece como tránsito necesario en los misterios del amor ${ }^{55}$; para alcanzar lo verdadero, es

utilizando un argumento apologético milenario ya para entonces — se remonta, de hecho, a las más antiguas defensas de Homero- sobre el modo «velado» («sotto velo di poesia») del «Giudizio Finale», en este caso, problematizado en su contenido e instrumentado ambiguamente como señal de los límites de pertinencia para la obra miguelangelesca, frente al ideal pictórico de Dolce (Raffaello). Por su parte, Mario Guiducci (1863: CXIV) alabó las interpretaciones de Varchi, señalando contrastivamente a los lectores que «non abbiano penetrato oltre alla superficie e corteccia di questi versi». Sobre el tema de la «bifrontalità, ambiguità e doppieza di ogni cosa» expresado en la visión miguelangelesca del arte, véase Folliero-Metz (2004: 271 ss.).

${ }^{54}$ Véase el comentario sobre el pasaje de Marsias realizado por el hijo del poeta, Pietro Alighieri (2002: 515-516); Apolo es no solo la «ciencia intelectual y especulativa» sino, él mismo, la personificación de la ficción poética que le sirve a aquella de instrumento, pues solo a través de su «canto» es capaz de dar cuenta de aquel contenido transcendente; la visión utiliza, de este modo, el «velamen fantástico» para mostrar y descubrir lo inexpresable apropiándose de su negatividad.

${ }^{5}$ Recuérdese, en el mismo territorio de la alegoresis mitológica, la exégesis de Giovanni Pico della Mirandola (1942: 555-556) a un pasaje del Symposium, donde se comenta, por boca de Fedro, que el fracaso de Orfeo consistió en habérsele entregado en el Hades, no a 
indispensable renunciar a lo parcial e ilusorio que la phantasía tiene como "puente" entre lo sensible y lo espiritual, así como el espíritu debe separarse del cuerpo para acceder a la región de lo divino que le es propia y que constituye la meta verdadera de la aspiración ascensional de la experiencia erótica; para ello debe transcenderse inexcusablemente lo sensual como mera "potencia" para "volver acto" la belleza, que demanda «levar' totalmente la natura de la materia» (Leone Ebreo 1929: [III], fol. 48v). Las expresiones más altas del arte miguelangelesco en su período de madurez abordan significativamente el tema de las postrimerías, la muerte y el destino ultramundano del alma - las tumbas de los Medici, el Giudizio-, y trazan una consecuente trayectoria de sentido con su alegorismo y su vocación transcendente, que marcan de modo inexorable el valor transitorio de la propia phantasía artística ${ }^{56}$ (también una forma de «vestidura» para el intelecto) ${ }^{57}$. Asimismo, por ejemplo, en una alegoría como Il Sogno la inspiración superior parece "invocar" o "insuflar" al hombre, dentro de los propios sueños del arte, una visión más alta que lo despierte por encima de las "máscaras" y "fantasmas" del mundo (los "vestidos" y "máscaras" del cuerpo y de su propia phantasía): «Ciascun de' Sogni drento alle lor larve / gli si fe' incontro, e '1 viso discoverse» ${ }^{58}$ (Stanze II,

Eurídice, sino a un fantasma (179d), ya que, por cobardía, no se atrevió a morir por amor; de acuerdo con Pico, la falencia del mítico cantor radicó en echar mano de una facultad inferior, la phantasia, incapaz de aprehender la esencia de la idea.

${ }^{56}$ Donde incluso se le puede atribuir, como hace Balas (1995: 161), al neoplatonismo y su alegoría críptica un fin soteriológico que incluye al propio artista: «Michelangelo constructed a scheme of Macro and Microcosmos, a cryptic magical world of potent allegorical images in conjunction with philosophical principles striving for a lofty goal: redemption for himself, as a divine artist, and also for the Medicis»».

${ }^{57}$ Véase el conocido estudio de Klein (1970).

${ }^{58}$ El sentido de larva (semejante al griego mormolukeîn, «the word larva in Latin and in the Italian vernacular means 'mask' as well as 'ghost', 'bugbeat', or 'phantasm'») y el pasaje de Poliziano ha sido destacado por Dempsey, quien lo ha puesto en relación con la máscara que acompaña a la Notte en la Capilla Medici, símbolo que en dicho contexto alude de diversos modos al tema de la vanitas (las que corresponden al duque Lorenzo y Giuliano representan «the empty larva of earthly riches [...] the larvate insignia of military prowess and ambition», etcétera); véase Dempsey (2001: 103 y 220-222). Esto mismo ha sido vinculado con las máscaras debajo del arca donde yace la figura central de Il Sogno por Maria Ruvoldt (2004: 177 y 216 n. 94), quien menciona además de modo sugestivo a este propósito la conocida carta de Annibale Caro a Taddeo Zuccaro sobre el proyecto del Palazzo Farnese en Caprarola; Caro señala que deberá tratarse en la decoración del dormitorio del cardenal (la Camera dell'Aurora) el tema de la Casa del Sueño de Ovidio incluyendo «maschere di variati mostacci». Van den Doel (2008: 197) registra esta interpretación con su índole negativa («de bedrieglijke keerzijde van phantasia en imaginatio»), con diversos matices e implicaciones, como la máscara que simboliza a la mímesis en la figura de la Pittura de Ripa. Para una valoración general del dibujo del $\mathrm{Il}$ sogno como alegoría de la inspiración, el furor, la melancolía y la phantasía, véase el 
24e-f; Poliziano 1997: I, 36). El arte se asocia con la faceta sombría de la vis phantastica, vinculada con la inconsciencia nocturna y la cárcel de la materia ${ }^{59}$, y la personalidad humana del artista mismo se revela por su vía como una terrible "máscara" imaginaria ${ }^{60}$.

\section{CONCEPCIONES FINALES}

En términos contextuales, cabe sostener que las reflexiones contenidas en las Rime suponen una forma peculiar, y acaso su expresión más sugestiva, del idealismo estético de inspiración neoplatónica en el ámbito de la literatura artística del alto Renacimiento italiano ${ }^{61}$. Esto se expresa, en un primer plano, en la temática amorosa. Según lo visto, el proceso erótico descrito en la poesía de Michelangelo empata con figuras y nociones que provienen en muchos casos de las enseñanzas del maestro de la Academia y milenariamente desarrolladas por numerosos continuadores o que en algún grado se asumieron como tales; y aun si la fuente y mediación dantesca revela también su alta pertinencia, probablemente no pueda operar de forma tan sistemática, al modo del neoplatonismo, para explicar de manera transversal el imaginario miguelangelesco. La forma bella es un «concepto imaginado interiormente»; parte en efecto de la vista entendida con una cualidad activa que da fundamento a la imagen poética de los ojos que arrojan «saetas»; el blanco de estas es la sede, corpórea e inmaterial, del corazón, residencia de la fantasía y la memoria. En este despliegue se asume una constante depuración, donde la manifestación sensible de la belleza está al inicio de un camino que, a través de las fuerzas iluminativas y receptoras de la vista, da después lugar a la peculiar «alquimia» del corazón, donde las imágenes no solo son guardadas, sino que comienzan a transfigurarse, a "crecer" en el medio anímico y servir como peldaños de una escala que se proyecta hacia la Belleza.

mismo capítulo al respecto en Ruvoldt (2004: 141-187) y Doel (2008: 193-207); asimismo Buck (2010).

59 Según sugiere Campbell (2002: 609b): «The artist's capacity to form images is identified not with Dante's alta fantasia but with the nocturnal domain of dreams, of ghosts and illusions, not with a higher power of the mind but displaced downward, grounded in the lower body - specifically, in Night's involuntary generation of forms from her womb; she gives birth to an owl, to poppies, and to inchoate forms left incomplete by the sculpture». Dicha identificación con la «noche» la apoyan sonetos (104, 13: «mia oscura notte») «composed in tandem with his work on the chapel».

${ }_{60}$ «The flayed skin in The Last Judgment has the status of a mask; an entire body, putatively that of the autor, has been turned into a larva, an empty and inanimate persona void of inspirating energy» y puede ser entendido como «a not-self or antiportrait» (Campbell 2002: 611a y 614a).

${ }_{61}^{6}$ Con acierto, Folliero-Metz (1996: 466-467) lo destaca como la expresión más completa de la estética idealista del Renacimiento que inicia con Alberti. 
Por su parte, la erótica de espíritu neoplatónico se entrelaza con expresiones más distintivas del poeta como creador de metáforas del arte, mostrando también al amor como magister artium (Ficino 2002: 57). En este ámbito aparecen imágenes más o menos comunes a la poesía, como la metáfora de la escultura o pintura en el corazón, pero también algunos antiguos tópicos resultan significativamente incorporados y transfigurados. Así, la originalidad del tratamiento de la aphaíresis en los poemas de Michelangelo tiene que ver con la mezcla de su sentido artístico y moral con el proceso erótico de la philía — de palmaria ascendencia neoplatónicay el desarrollo espiritual del amante-artista. Es notable que la imagen en él adquiere un inédito poderío, probablemente por la profunda empatía y la comprensión práctica y «emocional» que el artista tiene frente a ella y que involucra, con una valencia múltiple, la «materialidad» de la piedra, el cuerpo y el lenguaje mismo inusualmente substancializado - a nivel no solo del léxico, sino de la sintaxis ${ }^{62}$-, acrisolando la afortunada unidad de forma-contenido de su expresión poética. Como ha sucedido en otros momentos de la literatura artística del Renacimiento, una figura del pensamiento metafísico es reasumida por aquella, convirtiéndola en este caso en una metáfora éstetica —al tiempo que metáfora existenciaria - por excelencia, donde lo material se objetiva en su manifestación extrema como alteridad dinámica frente al espíritu, tensando el páthos todo de su naturaleza como vivencia y como representación; ello arroja luz sobre la propia obra plástica de Michelangelo y su agonismo sublime - proyectado también a lo ciclópeo ${ }^{63}$-, donde la más extrema corporización de lo ideal $-\mathrm{y}$ su inversa idealización de lo corpóreo - en la historia de Occidente sirve al propósito de revelar al cuerpo, en toda la terribilità de su patencia, como sýmbolon y allegoría del espíritu. Así, en su dimensión metafísica, el espíritu y su poder y su impotencia — su pasión - ante la materia - habitación y cárcel de la idea - se objetiva, plástica y poéticamente, en esta metáfora artística que es cifra del idealismo demiúrgico miguelangelesco (el kósmos como «obra y prisión» del espíritu).

En la disyuntiva entre los ojos del cuerpo / los ojos del alma, la renuncia a lo precario e incompleto de las manifestaciones materiales (con todo el esplendor

62 «One who, speaking of the poems, defined Michelangelo’s vocabulary as a vocabulary of "substances" could concede that in another sense this substantial quality is confirmed by a syntax that while never enfeebling the semantic backbone of the word, not even in the melodious passages, makes the word into a solid palpable being, a visual datum» (Nencioni 1966: 564). Piénsese en el lenguaje ensayado por Dante en las Rime petrose XLIII-XLVI, en particular ésta última (Alighieri 1965: 165-171).

${ }_{63}$ Así lo muestra el sueño miguelangelesco de esculpir una figura colosal de una montaña de Carrara, emulación del célebre proyecto de Dinócrates, según refiere Condivi (1998: 23), y, a pesar de su aire fabuloso, confirma una postilla de Calcagni (1998: XXI): «L. Questa era, disse, una pazzia venutami per detta. Ma s'io fusse sicuro di vivere 4 volte quanto son vissuto, sare'vi io entrato» (10). Como apunta Caroline Elam (1998: XLII) al respecto: «Michelangelo's fantasy encapsulates all his heroic engagement with his primal material and the figures locked within it». 
visual de la belleza y el «superchio lume» $(113,7)$ y el «leggiadro e mortal velo» donde Dios «si specchia» $\left(106,13-14^{64}\right)$, reviste a veces la forma de lo terrible en la imaginería demiúrgico-sacrificial de la poesía miguelangelesca. En sus últimos años se manifiesta también explícitamente, en un tono de inquieta melancolía, el tema de la vanitas, donde el pensamiento de la muerte se vuelve omnipresente (en su boca pone Giannotti (1939: 69) una apología de él). Este asunto central del orbe manierista-barroco se expresa también en una famosa carta del 22 de junio de 1555 a Giorgio Vasari, en los términos de la alegoría de la escultura interior: «e non nasce in me pensiero che non vi sia dentro sculpita la morte» (418; Buonarroti 1976: 288); cada pensamiento es la «materia mental» donde el artista descubre la imagen ominosa y destructora, el germen de su negatividad que lo consume desde dentro. La recurrencia de estas metáforas refleja la dimensión "interior" de la concepción escultórica de Michelangelo, ese deinòs plástes, il terribile scultore cuya potencia creadora, como en el símil platónico, corresponde al poder plasmante del pensamiento imaginario (Respublica IX, XII, 588c-d), pero que se convierte también en la vía canceladora de la posibilidad de su sentido, en el implacable movimiento de una estética que se ve "removida" por la metafísica apofática que la dotó de sentido.

Esta postura teórica - explicada también, de distinta manera, en un conceptuoso e iluminador "juego de ingenio" 65 -, tiene sus correlatas expresiones en la poesía tardía, vertidas en su propio lenguaje que corresponde con el mayor celo religioso característico del período final del artista, azuzado tal vez por los rigores postridentinos y la sensación acuciante del fin de la propia existencia. Ello no deja de afectar también la visión del creador frente a la phantasía artística y sus endebles posibilidades salvíficas:

Giunto è già ' 1 corso della vita mia, con tempestoso mar, per fragil barca, al comun porto, ov'a render si varca conto e ragion d'ogni opra trista e pia.

Onde l'affettüosa fantasia che l'arte mi fece idol e monarca conosco or ben com'era d'error carca e quel c'a mal suo grado ogn'uom desia.

Gli amorosi pensier, già vani e lieti,

64 El tópico aparece muchas veces en la poesía de Michelangelo, con diferentes designaciones: «el mie terrestre velo» $(209,2 ; 215,4)$, o «sott'un candido velo» $(265,4)$; a veces el «velo» de la carne reviste la dureza del muro (estrechándose así su vínculo con el motivo de la cárcel corpórea): «Squarcia 'l vel tu, Signor, rompi quel muro / che con la suo durezza ne ritarda / il sol della tuo luce, al mondo spenta!» (87, 9-11); etcétera. 202).

${ }^{65}$ Cf. Buonarroti (1970: 368-369) y los pertinentes comentarios de Summers (1981: 200- 
che fien or, s'a duo morte m'avvicino?

D'una so 'l certo, e l'altra mi minaccia.

Né pinger né scolpir fie più che quieti

l'anima, volta a quell'amor divino

c'aperse, a prender noi, 'n croce le braccia ${ }^{66}$. (285)

La "apasionada fantasía” que entronizó el arte cae junto con «los pensamientos amorosos»; ni pintar ni esculpir aquietan el alma que busca solo el Amor divino (Cristo), y en las "fantasías artísticas" se torna más apremiante la consciencia de su condición deficitaria, ya que, aun superando a los sentidos, la propia "estatua" interior - en palabras de Ficino - que crea el nimio y temerario artesano de la phantasía («transcender la fantasía es algo no menos difícil que beatificante», afirmó Sinesio: De insomniis VII, 137C) se revela imperfecta y al final puede engañar como la obra de un "sofista",67. O en todo caso, utilizando unas palabras de Lorenzo de' Medici, el alma debe prepararse a pasar de la dolcezza de la immaginazione posible en este mundo a la que toca a la contemplación de la "bondad divina"68. Así la tendencia ascética — «im Stile», apuntó Borinski (1908:

${ }^{66}$ El tópico crístico de los brazos abiertos en la salvación aparece en otros loci; así: «Signor, nell'ore streme, / stendi ver' me le tue pietose braccia» $(161,15-17)$.

67 En su fallida figuración interior de Dios: «Quando animus noster, quid deus sit cupiens invenire, a magistris huiusmodi sciscitatur, phantasia praeceptor et faber nimium temerarius statuam aliquam machinatur ex quinque materiis, quas aliarum omnium pulcherrimas externi sensus ipsi obtulerint, acceptas a mundo, eo tamen pacto ut materias illas excellentiores reddat quodammodo quam a mundo per sensus acceperit... Sed ratio interim e summa mentis specula despiciens phantasiae ludos, ita proclamat: "Cave animula, cave inanis istius sophistae praestigias"》 (Theologia platonica IX, III, 2-3; Ficino 2003: III, 18). La relación especular entre arte y phantasía es reiterada por Ficino, esa sustentable identidad «che esiste tra l'attività fantastica e quella artistica: phantasia e imaginatio sono infatti ripetutamente definite come faber, pictor e sculptor» (Tirinnanzi 2000: 23-24). Luego, esta semejanza resulta operativa en términos de los límites comunes al arte y las operaciones imaginarias en general en el ascenso a lo inteligible; a aquella $-\mathrm{y}$ bien lo muestra la obra de Michelangelo - se le puede atribuir también la condición de umbra en su plenitud fenoménica y como propiciatoria de la fallacia phantasiae que produce de modo "perverso" "la convinzione di una identità quasi assoluta tra forma e materia» (Tirinnanzi 2000: 124), alimentada con la noción de la propia potencia demiúrgica de un arte que "extrae" la forma que "yace" en la materia.

${ }^{68}$ Hay, a pesar de sus irreductibles diferencias, una relación de semejanza en las visiones de "beatitud" en el mundo con la participación contemplativa — también por mediación de la phantasía - de la bondad divina: «che la dolcezza della immaginazione ha qualche similitudine colla vera beatitudine, cioè quella che consegue l'anima a cui è data la gloria etterna, la quale in altro modo non si fruisce che immaginando e contemplando la bontà divina. E benchè questa contemplazione sia differente assai dalla contemplazione umana, perché quella contempla el vero e questa una immaginazione vana che forma l'appetito 
48), «der platonischen Antipoetik»— censura lo imaginario que recubre al mundo sensible por entero («Le favole del mondo»; 288, 1), la máscara engañosa de la vanitas que se convierte en un estorbo para el progreso espiritual; desde el interior mismo del sueño del arte se invoca al despertar del sueño del mundo y su mascarada espectral. Poesía en intensa pugna consigo misma, en este tramo final asume el término inevitable donde el agonismo demiúrgico prepara su autocancelación y su entrega al silencio. La acentuada religiosidad final de la lírica miguelangelesca coincide con los límites propios al arte asumidos por la doctrina y la poesía cristianas (así el ejemplo maestro de Dante y el cierre de la Commedia: «A l'alta fantasia qui mancò possa...»" ${ }^{69}$, Paradiso XXXIII, 142 [Alighieri 1967, IV: 557]), e incide negativamente en la insatisfactoria conciliación entre las esferas sensible e inteligible, que el arte y la erótica han tratado de conectar, para encontrar la insubstancialidad neoplatónica del cuerpo y la phantasía y sus destinos entrelazados; efímera unidad en la plástica cuya juntura y nuevo desgarramiento abre el abismo ontoteológico que reviste el sello paulino y contrarreformista ${ }^{70}$, donde no cabe ver concluidas las imágenes interiores y los anhelos del espíritu sino «después de ser removido el velo del cuerpo» (san Basilio de Ancira, De virginitate 30; Patrologia Graeca XXX, col. 732;). Trayectoria hacia lo invisible que, sin embargo, corresponde armónicamente con la intentio transcendental que encauza, desde su origen, la búsqueda de Platón, sobre todo en las modalidades características de sus discípulos en la Antigüedad tardía y el Renacimiento. Su posible unidad doctrinal aparece ya en tempranos autores de índole hondamente sincrética, neoplatónico-cristiana, como Sinesio de Cirene:

Difícil desplegar por entero

el corazón en las alas totales

mortale, nondimeno l'una coll'altra ha qualche poco de similitudine nel mo[n]do» (Comento de' miei sonetti, «Nuovo argumento», XXI, 19-20; Lorenzo de' Medici 1992: I, 458).

${ }^{69}$ Se trata, en el caso de la conclusión de la Commedia, de la claudicación del arte frente a lo absoluto (señalada en Phaedrus 247c3-4); pero cabe recordar que las limitaciones de la phantasía quedan expresadas en otros pasajes, como en la visión que «l'alta fantasia» misma revela, interiormente - mostrando su pertenencia fundamental a esta esfera-, de la crucifixión dantesca de Amán; al momento, la imagen se desvanece — dando paso a la figura de Lavinia-, en un símil que sugiere con sutil justeza lo frágil y pasajero de sus dones: «E come questa imagine rompeo / sé per sé stessa, a guissa d'una bulla / cui manca l'acqua sotto qual si feo» (Purgatorio XVII, 31-33; Alighieri 1967: III, 282).

${ }^{70}$ Es necesario matizar, sin embargo, el influjo contrarreformista en los años finales de Michelangelo; en palabras de Clements (1961: 398): «The Counter Reformation was not an historical force which altered Michelangelo's fundamental theories on the religious inspiration or application of the fine arts, or any of his theories whatsoever, so far as can be judged». Se puede hablar, sí, de un fuerza intensificatoria de ciertas tendencias presentes de tiempo atrás en el pensamiento del artista, azuzadas quizás por razones biográficas propias del período (estando ya «negli ultim'anni della vita mia»; 286, 2), con la creciente idea de la presencia de la muerte. 
de los amores que elevan.

Sólo mantén el impulso

en los cantos que a lo intelectual conducen;

entonces para ti cerca aparece

el Padre, que extiende los brazos;

pues un rayo corriendo delante

iluminará sobre los caminos,

y abrirá para ti la llanura

inteligible, principio de la belleza. (Himnos v, 117-127)

\section{REFERENCIAS BIBLIOGRÁFICAS}

AlBerTI, Leon Battista [GRAYSON, Cecil] (1960-1973): Opere volgari, III vols., a cura di Cecil Grayson, Roma, Laterza.

AlBERTI, Leon Battista [BÄTSCHMANN, Oskar / SCHÄUBLIN, Christof] (2000): Das Standbild, Die Malkunst, Grundlagen der Malerei, herausgegeben von Oskar Bätschmann / Christof Schäublin, Darmstadt, Wissenschaftliche Buchgesellschaft.

AlighiERI, Dante [CONTINI, Gianfranco] (1965): Rime, a cura di Gianfranco Contini, Torino, Einaudi.

Alighieri, Dante [Petrocchi, Giorgio] (1966-1967): La Commedia secondo l'antica vulgata, IV vols., a cura di Giorgio Petrocchi, Milano, Arnoldo Mondadori [Società Dantesca Italiana, Edizione Nazionale].

Alighieri, Dante [ConTINI, Gianfranco] (1984): Il Fiore e Il Detto d'amore attribubili a Dante Alighieri, a cura di Gianfranco Contini, Milano, Arnoldo Mondadori.

AlighiERI, Dante [BRAmbilla AgEno, Franca] (1995): Convivio, vol. II: Testo, a cura di Franca Brambilla Ageno, Firenze, Società Dantesca Italiana, Edizione Nazionale, Le Lettere.

AlighIERI, Dante [GORNI, Guglielmo] (1996): Vita Nova, a cura di Guglielmo Gorni, Torino, Einaudi (Nuova raccolta di classici italiani annotati, 15).

Alighieri, Pietro [CHIAMENTI, Massimiliano] (2002): Comentum super poema Comedie Dantis. A Critical Edition of the Third and Final Draft of Pietro's Alieghieri's Commentary on Dante's The Divine Comedy, edited by Massimiliano Chiamenti, Arizona, Arizona Center for Medieval and Renaissance Studies.

ANDREAS CAPELlanus [TROJEL, Emil] (1972 [1892]): Andreas Capellanus regii Francorum De amore libri tres, recensuit Emil Trojel (ed.), København, Gadiana [facsímil: Münich, Wilhelm Fink].

ARIOSTO, Ludovico [SEGRE, Cesare] $\left(1998^{7}\right)$ : Orlando furioso, a cura di Cesare Segre, Milano, Mondadori. 
Averlino, Antonio detto Il Filarete [FinOli, Anna Maria / Grassi, Liliana] (1972): Trattato di architettura, II vols., a cura di Anna Maria Finoli / Liliana Grassi, Milano, Il Polifilo.

BALAS, Edith (1995): Michelangelo's Medici Chapel: A New Interpretation, Philadelphia, American Philosophical Society.

BELlORI, Giovanni Pietro (2000 [1672]): Le vite de' pittori, scultori et architetti moderni, Roma, Per il Success. al Mascradi [ed. fototípica, Arnaldo Forni, Bologna].

BEMBo, Pietro [Dilemmi, Giorgio] (1991): Gli Asolani, a cura di Giorgio Dilemmi, Firenze, Accademia della Crusca (Scrittori italiani e testi antichi pubblicati dall'Accademia della Crusca).

BENVENUTO DA IMOLA (Benvenuto de' Rambaldi) [LACAITA, Giacomo Filippo] (1887): Comentum super Dantis Aldigherij Comoediam, V vols., edidit Giacomo Filippo Lacaita, Firenze, Barbera.

Berni, Francesco [ChIÒrboli, Enzo] (1934): Poesie e prose, a cura di Ezio Chiòrboli, Ginevra / Firenze, L. S. Olschki (Biblioteca dell'"Archivum Romanicum», Serie I: Storia, Letteratura, Paleografia, 20).

BLUNT, Anthony (1994): Artistic Theory in Italy. 1450-1600, Oxford, Oxford UP.

BOCCACCIO, Giovanni [BRANCA, Vittore] $\left(1999^{7}\right)$ : Decameron, a cura di Vittore Branca, Milano, Arnoldo Mondadori.

BORINSKI, Karl (1908): Die Rätsel Michelangelos. Michelangelo und Dante, Münich, Georg Müller.

BranN, Noel L. (2002): The Debate over the Origin of Genius During the Italian Renaissance. The Theories of Supernatural Frenzy and Natural Melancholy in Accord and in Conflict on the Threshold of the Scientific Revolution, Leiden / Boston, Brill.

BRUNO, Giordano (1962 [1890]) [TocCO, Fiorentino et alii]: Jordani Bruni Nolani Opera Latine conscripta, vol II, pars II: 1. De Architectura Lulliana, 2. Ars reminiscendi, Triginta sigilli etc., Sigillus Sigillorum, 3. Centum et viginti Articuli de natura et mundo, 4. De Lampade combinatoria et De specierum Scrutinio, 5. Animadversiones in Lampadem Lullianam ex codice Augustano nunc primum editae, curantibus F. Tocco et alii, Florentia, Typis Successorum Le Monnier [repr. facsímil Stuttgart / Bad Cannstatt, Friedrich Frommann / Günther Holzboog].

BUCK, Stephanie (ed.) (2010): Michelangelo's Dream, London, The Courtlaud Gallery / Paul Holberton.

BuONARROTI, Michelangelo [GuASTI, Cesare] (1863): Le rime di Michelangelo Buonarroti, pittore, scultore e architetto, a cura di Cesare Guasti, Firenze, Felice Le Monnier.

BuONARROTI, Michelangelo [FREY, Carl] (1897): Die Dichtungen des Michelagniolo Buonarroti, herausgegeben von Carl Frey, Berlin, G. Grote.

BuONARROTI, Michelangelo [GIRARDI, Enzo Noè] (1960): Rime, a cura di Enzo Noè Girardi, Bari, "Scrittori d'Italia", 217, Giuseppe Laterza \& Figli. 
Buonarroti, Michelangelo [BARDESCHI CiUlich, Lucilla / BAROCCHI, Paola] (1970): I Ricordi di Michelangelo, a cura di Lucilla Bardeschi Ciulich / Paola Barocchi (eds.), Firenze, Sansoni.

BUONARROTI, Michelangelo [GIRARDI, Enzo Noè] (1976): Lettere, a cura di Enzo Noè Girardi, Arezzo, Ente Provinciale per il Turismo.

BuONARROTI, Michelangelo [BAROCCHI, Paola] (1998): «Carta "Al molto magnifico et onorando M. Benedetto Varchi, suo osservandissimo"», in Benedetto Varchi / Vincenzo Borghini: Pittura e scultura nel Cinquecento, a cura di Paola Barocchi, Livorno, Sillabe, p. 84.

BYron, George Gordon [HARTLEY, Ernst] (Lord) (1948): The Poetical Works of Lord Byron. The Only Complete and Copyright Text in One Volume, edited by Ernst Hartley Coleridge (ed.), London, John Murray.

CAlCAGni, Tiberio [Nencioni, Giovanni] (1998): «Postille to Condivi's "Vita di Michelagnolo"», in Ascanio Condivi, Vita di Michelagnolo Buonarroti, a cura di Giovanni Nencioni, Firenze, Studio Per Edizioni Scelte, pp. XXI-XXII.

CAMPBELL, Stephen J. (2002): «"Fare una Cosa Morta Parer Viva”: Michelangelo, Rosso, and the (Un)Divinity of Art», Art Bulletin, LXXXIV: 4, pp. 596-620.

Cattani DA Diacceto, Francesco (1561): I tre libri d'amore. Di M. Francesco Cattani da Diacceto, filosofo et gentil'huomo Fiorentino, con un Panegerico all'Amore; et con la vita del detto Autore, fatta da M. Benedetto Varchi, Venezia, apprèsso Gabriel Giolito de' Ferrari.

CAVAlCANTI, Guido [DE RoBerTis, Domenico] (1986): Rime, a cura di Domenico de Robertis, Torino, Einaudi.

CECCO, d'Ascoli [CRESPI, Achille] (1927): L'acerba. Ridotta a miglior lezione e per la prima volta interpretata col sussidio di tutte le opere dell'autore e delle loro fonti, a cura di Achille Crespi, Ascoli Piceno, G. Cesari.

ClEMENTS, Robert J. (1961): Michelangelo's Theory of Art, Nueva York, Gramercy.

ColonNA, Franceso [ARIANI, Marco / GABRIELE, Mino] (2004): Hypnerotomachia Poliphili, I: Riproduzione dell'edizione aldina del 1499 [Venecia, In aedibus Aldi Manutii, 1499], a cura di Marco Ariani / Mino Gabriele, Milano, Adelphi.

CONDIVI, Ascanio [NENCIONI, Giovanni] (1998): Vita di Michelagnolo Buonarroti, a cura di Giovanni Nencioni, Firenze, Studio Per Edizioni Scelte.

DOEL VAN DEN, Marieke J. E. (2008): Ficino en het voorstellingsvermogen. "Phantasia" en "imaginatio" in kunst en theorie van de Renaissance, Amsterdam, "Academisch proefschrift, Universiteit van Amsterdam", St. HoofdHart-Handen.

DOLCE, Lodovico [BAROCCHI, Paola] (1960): Dialogo della pittura, in: Paola Barocchi (a cura di), Tratatti d'arte del Cinquecento, vol. I, Bari, "Scrittori d'Italia", 219, Gius. Laterza \& Figli, pp. 141-206.

DÜRER, Albrecht [LANGE, Conrad / FUHSE, Franz Luis] (1893): Dürers Schriftlicher Nachlass, auf Grund der Originalhandschriften und theilweise neu entdeckter alter Abschriften, eherausgegeben von Conrad Lange / Franz Luis Fuhse, Halle, Max Niemeyer. 
Elam, Caroline (1998): «"Che ultima mano?": Tiberio Calcagni's "Postille to Condivi's Life of Michelangelo"», in Ascanio Condivi: Vita di Michelagnolo Buonarroti, a cura di Giovanni Nencioni, Firenze, Studio Per Edizioni Scelte, pp. XXIII-XLVI.

EQUICOLA, Mario (1536): Libro di natura d'amore di Mario Equicola, novamente stampato, et con somma diligentia corretto, Venezia, Nelle case di Pietro di Nicolini da Sabbio.

ERASMO DE ROTTERDAM (1514): Adagiorum Chiliades tres, ac centuriae fere totidem, Tubinga, in aedibus Thomae Anshelmi Badensis.

FICINO, Marsilio (1576): Marsilii Ficini Florentini, insignis philosophi Platonici, medici, atque theologi clarissimi, Opera, \& quae hactenus extitere, \& quae in lucem nunc primum prodiere omnia [...], II vols., Basilea, Ex Officina Henricpetrina.

Ficino, Marsilio [Hankins, James / Bowen, William] (2001): Platonic Theology, vol. I: Books I-IV, Latin Text Edited by James Hankins with William Bowen, "The I Tatti Renaissance Library", Cambridge (MA) / London, Harvard University Press.

Ficino, Marsilio [Hankins, James / Bowen, William] (2003): Platonic Theology, vol. III: Books IX-XI, Latin Text Edited by James Hankins with William Bowen, "The I Tatti Renaissance Library", Cambridge (MA) / Londres, Harvard University Press.

Ficino, Marsilio [LAurens, Pierre] (2002): Commentaire sur «Le Banquet» de Platon, "De l'amour». Commentarium in Convivium Platonis, De amore, texte établi et traduit par Pierre Laurens, Paris, Les Belles Lettres.

Flasch, Kurt (1997): «Nicolaus Cusanus, Vom Sehen Gottes», Micrologus. Natura, scienze e società medievali. Nature, Sciences and Medieval Societies, V: La visione e lo sguardo nel Medio Evo. View and Vision in the Middle Ages, vol. I, [Firenze, Sismel-Del Galuzzo], pp. 107-118.

FolLIERO-METZ, Grazia Dolores (1996): «Una testimonianza diretta della teoria michelangiolesca dell'arte: le rime d'arte», Romanische Forschungen, 108: 3-4, pp. 462-473.

FolLIERO-MetZ, Grazia Dolores (2004): Le "Rime" di Michelangelo Buonarroti nel loro contesto, prefazione di Enzo Noè Girardi, Heidelberg, "Studia Romanica", 121,Universitätsverlag Winter.

FRATI, Lodovico (ed.) (1913): Le rime del Codice Isoldiano (Bologn. Univ. 1739), vol. II, Bolonia, "Collezione di opere inedite o rare dei primi tre secoli della lingua, pubblicata per cura della Regia Commissione pe' Testi di Lingua, nelle provincie dell'Emilia", Romagnoli / Dall'Acqua.

GARIN, Eugenio (1966): «Thinker», in The Complete Work of Michelangelo, Reynal and Company, New York, pp. 517-530.

GiannotTI, Donato [Redig DE CAMPos, Deoclecio] (1939): Dialogi de Donato Giannotti, de' giorni che Dante consumò nel cercare l'Inferno e 'l Purgatorio, a cura di Deoclecio Redig de Campos, "Raccolta di fonti per la storia dell'arte", II, Firenze, G. C. Sansoni. 
GIRARDI, Enzo Noè (1966): «Writer», en The Complete Work of Michelangelo, Reynal and Company, Nueva York, pp. 531-556.

GUIDUCCI, Mario (1863): «Lezione prima di Mario Guiducci, fatta nell'Accademia Fiorentina in occasione delle "Rime" date in luce di Michelagnolo Buonarroti», in Michelangelo Buonarroti: Le rime di Michelangelo Buonarroti, pittore, scultore e architetto, a cura di Cesare Guasti, Firenze, Le Monnier,pp. CXIII-CXXII.

HolANDA, Fancisco de [VASCONCELlos, Joaquín de] $\left(1930^{2}\right)$ : Da pintura antigua. Tratado de Francisco de Holanda. Contém: a) Livro primeiro - parte theorica, b) Livro segundo - Dialogos em Roma, edição de Joaquín de Vasconcellos, Porto, Renascença portuguesa.

KLEIN, Robert (1970): «L'imagination comme vêtement de l'âme chez Marsile Ficin et Giordano Bruno», en André Chastel (ed.), La forme et l'intelligible. Écrits sur la Renaissance et l'art moderne, Paris, Gallimard (N.R.F.), pp. 65-88.

LeONARDo DA Vinci [PedRetTI, Carlo / VeCCE, Carlo](1995): Libro di Pittura. Codice Urbinate lat. 1270 nella Biblioteca Apostolica Vaticana, II vols., a cura di Carlo Pedretti, trascrizione critica di Carlo Vecce, "Biblioteca della Scienza Italiana", IX, Firenze, Giunti.

LEONE EBREO (Yehuda Abrabanel) [GEBHARDT, Carl] (1929 [1535]): Dialoghi d'amore. Hebrceische Gedichte, herausgegeben von Carl Gebhardt, Heidelberg / Londres / París / Ámsterdam, Carl Winters Universitätsbuchandlung / Oxford University / Les Presses Universitaires / Menno Hertzberger, Curis Societatis Spinozanae [repr. de Dialogi d'amore di maestro Leone medico Hebreo, Roma, Antonio Blado d'Assola].

LOMAZZO, Giovanni Paolo [KLEIN, Robert] (1974): Idea del tempio della pintura, II vols., a cura di Robert Klein, Firenze, Nella sede dell'Istituto Palazzo Strozzi.

MAZzoni, Jacopo (1587): Della difesa della Comedia di Dante. Distinta in sette libri. Nella quale si risponde alle oppositioni fatte al Discorso di M. Iacopo Mazzoni, e si tratta pienamente dell'arte Poetica, e di molt'altre cose pertenenti alla Philosophia, \& alle belle lettere. Parte prima. Che contiene li primi tre libri, Cesena, Appresso Bartolomeo Rauerij.

MEDICI, Lorenzo de' [ORVIETO, Paolo] (1992): Tutte le opere, vol. I, a cura di Paolo Orvieto, Roma, Salerno Edizioni.

NENCIONI, Giovanni (1966): «Language», in The Complete Work of Michelangelo, Reynal and Company, Nex York, 1966, pp. 557-564.

PANOFSKY, Erwin $\left(1960^{2}\right)$ : Idea. Ein Beitrag zur Begriffsgeschichte der älteren Kunsttheorie, Berlin, Bruno Hessling.

PANOFSKY, Erwin $\left(1962^{2}\right)$ : «The Neoplatonic Movement and Michelangelo», in Erwin Panofsky: Studies in Iconology: Humanistic Themes in the Art of the Renaissance, "Harper Torchbooks", New York, Harper \& Row, pp. 171-230.

PARKER, Deborah (2010): Michelangelo and the Art of Letter Writing, Cambridge, Cambridge UP.

PERNIS, Maria Grazia (1993): «The Young Michelangelo and Lorenzo de' Medici's Circle», en Bernard Toscani (ed.), Lorenzo de' Medici: New Perspectives. Proceedings of the International Conference Held at Brooklyn College and the 
Graduate Center of the City University of New York, April 30-May 2, 1992, "Studies in Italian Culture", 13, Nueva York / San Francisco / Berna / Baltimore / Frankfurt am Main / Berlín / Viena / París, Peter Lang, pp. 143-162.

PETRARCA, Francesco [NERI, Ferdianado et alii] (1951): Rime, Trionfi e poesie latine, a cura di Ferdinando Neri / Guido Martellotti / Enrico Bianchi / Natalino Sapegno, Milano-Napoli, Riccardo Ricciardi.

PETRARCA, Francesco [BufAnO, Antonietta] (1975): Opere latine, vol. II, a cura di Antonietta Bufano, Torino, UTET.

PICO DElla MirandolA, Giovanni [GARIN, Eugenio] (1942): De hominis dignitate, Heptaplus, De ente et uno, e scritti vari, a cura di Eugenio Garin, Firenze, Vallecchi.

Poliziano, Angelo [BAusi, Francesco] (1997): Poesie volgari, II voll., a cura di Francesco Bausi, Manziana, Vecchiarelli.

Rossi, Niccolò de' [Brugnolo, Francesco] (1974): Il Canzoniere di Nicolò de' Rossi, vol I: Introduzione, testo e glossario, a cura di Furio Brugnolo, Padova, Antenore.

RUVOLDT, Maria (2004): The Italian Renaissance Imagery of Inspiration. Metaphors of Sex, Sleep, and Dream, Cambridge, Cambrige Univeristy Press.

RUVOLDT, Maria (2012): «Michelangelo's Slaves and the Gift of Liberty», Renaissance Quarterly, LXV: 4, pp. 1029-1059.

SCHLOSSER, Julius von (1924): Die Kunstliteratur. Ein Handbuch zur Quellenkunde der neueren Kunstgeschichte, Wien, Anton Schroll \& Co.

SNOW-SMITH, Joanne (1998): «Michelangelo's Christian Neoplatonic Aesthetic of Beauty in His Early Ouevre: the Nuditas Virtualis Image», en Francis AmesLewis / Mary Rogers (eds.), Concepts of Beauty in Renaissance Art, Hants / Vermont, Ashgate, pp. 147-162.

SUMMERS, David (1981): Michelangelo and the Language of Art, Princeton, Princeton University Press.

TACHAU, Katherine H. (1997): «"Et maxime visus, cuius species venit ad stellas et ad quem species stellarum veniunt". Perspectiva and Astrologia in Late Medieval Thought»: Micrologus V, numero straordinario, La visione e lo sguardo nel Medio Evo. View and Vision in the Middle Ages, vol. I, pp. 201-224.

TIRINNANZI, Nicoletta (2000): Umbra naturae. L'immaginazione da Ficino a Bruno, "Istituto Nazionale di Studi sul Rinascimento", 7, Roma, Edizioni di Storia e Letteratura.

TOLnAY DE, Charles (1948): Michelangelo, vol. III: The Medici Chapel, Princeton, New Jersey, Princeton UP.

TOLNAY DE, Charles (1954): Michelangelo, vol. IV: The Tomb of Julius II, Princeton, New Jersey, Princeton UP.

TORRI, Alessandro (ed.) (1995 [1827-1829]): L'Ottimo commento della Divina Commedia. Testo inedito d'un contemporaneo di Dante, citato dagli Accademici della Crusca, III vols., Pisa, presso Niccolò Capurro [facsimile: pref. Francesco Mazzoni, Bologna, Forni]. 
TURNER, John (2007): «Michelangelo's Interiority», Source: Notes in the History of Art, XXVII: 1, pp. 25-31.

Uguccione DA PISA [CECChInI, Enzo / Albizzoni, Guido] (2004): Derivationes, II vols., a cura Enzo Cecchini / Guido Albizzoni et alii, "Edizione Nazionale dei testi mediolatini", XI, Firenze, Edizioni Del Galluzzo.

VARCHI, Benedetto [BAROCCHI, Paola] (1960): «Della maggioranza e nobiltà dell'arti», in: Paola Barocchi (a cura di), Tratatti d'arte del Cinquecento, "Scrittori d'Italia", 219, vol. I, Bari, Giuseppe Laterza \& Figli, pp. 3-82.

VARCHI, Benedetto [GUASTI, Cesare] (1863): Lezione di Benedetto Varchi sopra il sottoscritto sonetto di Michelagnolo Buonarroti, en Michelangelo Buonarroti: Le rime di Michelangelo Buonarroti, pittore, scultore e architetto, pubblicate da Cesare Guasti, Firenze, Felice Le Monnier, pp. LXXXV-CII.

VASARI, Giorgio [BELlOSI, Luciano / ROSSI, Aldo] (1986): Le Vite de' piú eccellenti architetti, pittori, et scultori italiani, da Cimabue, insino a' tempi nostri. Nell'edizione per i tipi di Lorenzo Torrentino, Firenze 1550, II vols., a cura di Luciano Bellosi / Aldo Rossi, presentazione di Giovanni Previtali, Torino, Einaudi.

WIND, Edgar $\left(1968^{2}\right)$ : Pagan Mysteries in the Renaissance, London, Faber and Faber. 